\title{
Surface Treatment to Improve Corrosion Resistance in Lead-Alloy Coolants
}

\section{DOE Agency No.: DE-FG07-04ID14600}

\author{
Final Report
}

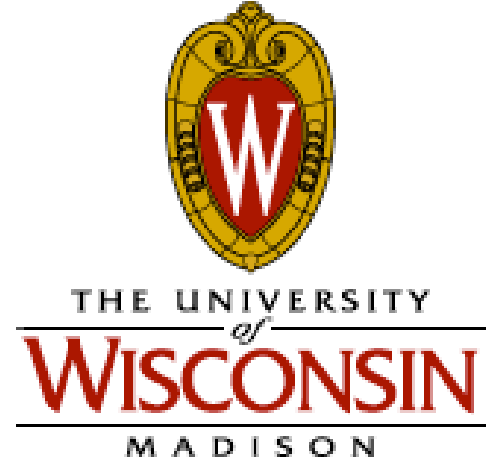

in collaboration with

Los Alamos National Laboratory, NM

August 2007 


\section{Table of Contents}

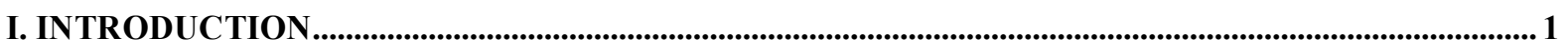

II. LITERATURE REVIEW ................................................................................................................. 1

III. CORROSION EXPERIMENTS .................................................................................................................. 3

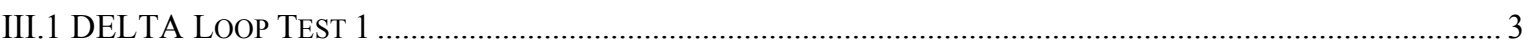

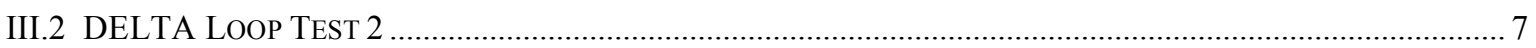

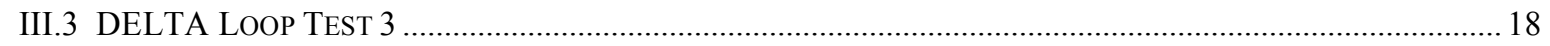

IV. OXIDATION AND CORROSION THEORY …….......................................................................................25

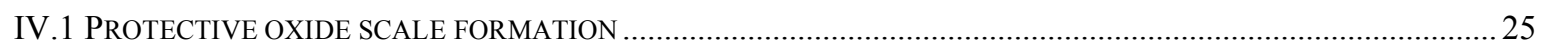

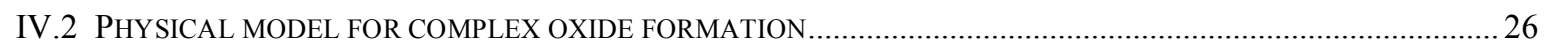

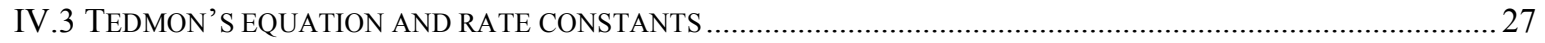

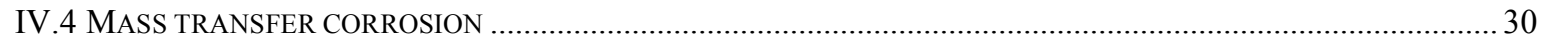

V. MODELING AND BENCHMARKING RESULTS.................................................................................31

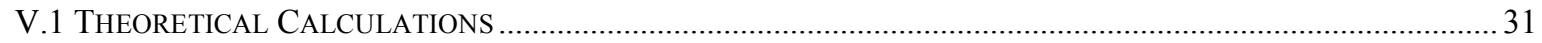

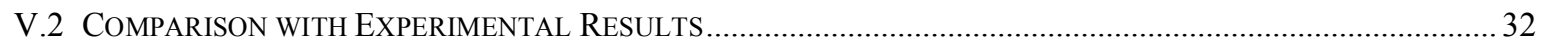

VI. CONSTRUCTION OF A MOLTEN LEAD CORROSION APPARATUS (MLCA) ................................33

VII. CONCLUSIONS..........................................................................................................................................................38

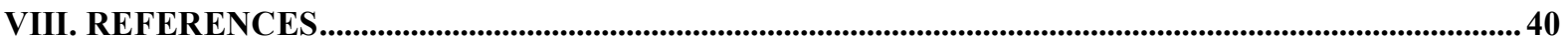

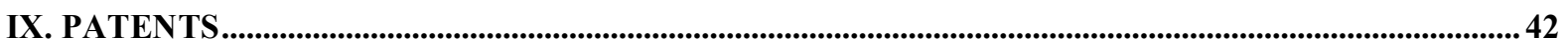

X. PUBLICATIONS.......................................................................................................................................................... 42

This report was prepared as an account of work sponsored by an agency of the United States Government. Neither the United States Government nor any agency thereof, nor any of their employees, makes any warranty, express or implied, or assumes any legal liability of responsibility for the accuracy, completeness, or usefulness of any information, apparatus, product, or process disclosed, or represents that its use would not infringe privately owned rights. Reference herein to any specific commercial product, process, or service by trade name, trademark, manufacturer, or otherwise does not necessarily constitute or imply its endorsement, recommendation, or favoring by the United States Government or any agency thereof. The views and opinions of authors expressed herein do not necessarily state or reflect those of the United States Government or any agency thereof. 


\author{
FY2006 Generation IV Lead Cooled Fast Reactor \\ Surface Treatment to Improve Corrosion Resistance in Lead-Alloy Coolants \\ University of Wisconsin \\ Nuclear Engineering and Engineering Physics \\ Final Report \\ DE-FG07-04ID14600 \\ July 2004 - July 2007
}

\author{
Todd R. Allen, Assistant Professor \\ Kumar Sridharan, Research Professor \\ McLean T. Machut, Graduate Student \\ Lizhen Tan, Postdoctoral Research Associate
}

\title{
I. Introduction
}

One of the six proposed advanced reactor designs of the Generation IV Initiative, the Leadcooled Fast Reactor (LFR) possesses many characteristics that make it a desirable candidate for future nuclear energy production and responsible actinide management. These characteristics include favorable heat transfer, fluid dynamics, and neutronic performance compared to other candidate coolants. However, the use of a heavy liquid metal coolant presents a challenge for reactor designers in regards to reliable structural and fuel cladding materials in both a highly corrosive high temperature liquid metal and an intense radiation field $^{\mathrm{i}}$. Flow corrosion studies at the University of Wisconsin have examined the corrosion performance of candidate materials for application in the LFR concept as well as the viability of various surface treatments to improve the materials' compatibility. To date this research has included several focus areas, which include the formulation of an understanding of corrosion mechanisms and the examination of the effects of chemical and mechanical surface modifications on the materials' performance in liquid lead-bismuth by experimental testing in Los Alamos National Laboratory's DELTA Loop, as well as comparison of experimental findings to numerical and physical models for long term corrosion prediction. This report will first review the literature and introduce the experiments and data that will be used to benchmark theoretical calculations. The experimental results will be followed by a brief review of the underlying theory and methodology for the physical and theoretical models. Finally, the results of theoretical calculations as well as experimentally obtained benchmarks and comparisons to the literature are presented.

\section{Literature Review}

The literature describes many attempts to understand the fundamental corrosion mechanisms of steels in liquid lead-alloys at temperatures from $460^{\circ} \mathrm{C}$ up to $600^{\circ} \mathrm{C}$ where they might be useful in application to an LFR ${ }^{\text {,ii,iii }}$. An excellent review of these and other prior experimental results and the fun ${ }^{\text {iv }}$ damental corrosion issues in lead-bismuth eutectic (LBE) is presented by Zhang and $\mathrm{Li}^{\mathrm{v}}$. Corrosion in a liquid lead-alloy can manifest itself in several forms including dissolution, compound formation, and liquid metal penetration along grain boundaries.

Several factors contribute to these corrosion mechanisms, including, temperature and thermal gradient, exposure time, flow rate, coolant chemistry, material compositions, and in particular the oxygen content of the melt. While a more complete discussion of these mechanisms and 
factors is presented in Section IV, the key issues to consider can be summarized as follows: Studies have shown that an oxygen content in the LBE of around $1 \times 10^{-6} \mathrm{wt} \%$ can form an oxide on the surface of steels, preventing dissolution of the steel. The oxide layers formed on Ferritic/Martensitic (FM) steels below $550^{\circ} \mathrm{C}$ generally have a double-layered structure consisting of an outer magnetite and inner Fe-Cr spinel. The studies to date also indicate that a change in corrosion mechanism occurs above $550^{\circ} \mathrm{C}$ requiring enhanced corrosion resistance for higher operating temperatures. Additionally, studies suggest that current materials may not be able to withstand the demanding lifetime requirements ( $>20$ years) for proposed reactor components (also see Section V). Based on these experimental findings, there has been a recent push to develop methods for improving corrosion performance of current materials by changing the surface properties of existing materials. This approach has the advantage of gaining corrosion performance enhancements without sacrificing bulk properties of the steel such as can be the case in alloying.

Elemental surface modification is one of the most common approaches in improving a material's corrosion resistance. The use of a material with an elemental surface treatment requires both uniform application and stability of the interface between the bulk material and the surface treated regions ${ }^{i}$. Plasma processing is one of the more innovative means of achieving this and is well suited for application to materials exposed to extreme environments. Although these processes have proven beneficial in applications such as biocompatible prosthetic joints in the medical industry and high-performing pistons in the automotive industry ${ }^{\mathrm{vi}}$, there has not been significant work done on plasma surface treatments for use in advanced nuclear systems. The research done on the effects of such modifications to date has been largely on materials in other extreme environments such as high temperature steam or supercritical water and salt or acid solutions ${ }^{\mathrm{vi}}$. However, promising results from these studies are based on scientific principles that should translate well to a lead or leadalloy environment. One technique for plasma processing that was developed at the University of Wisconsin-Madison is known as plasma immersion ion implantation and deposition (PIII\&D) ${ }^{\text {vii }}$. PIII can also be used to directly implant oxygen on the surfaces of steel specimen. In another plasma processing technique, a thin layer of metallic elements are first be deposited on the surface of the samples using sputter deposition, followed by inert ion (such as Xe or Ar) bombardment in the ion implantation system which aims to achieve adequate atomic mixing and stability.

Results from the initial corrosion experiments of this work (Sec III.2) exhibiting magnetite removal from the outer oxide surface of the steel specimens which were polished to a mirror finish (as opposed to an as-machined or lightly-polished condition) suggested that the surface roughness of the steel could have a significant effect on initial oxide formation and hence also on the long term corrosion performance of the steel. A literature search reveals a study by Kondo, et al. of the Tokyo Institute of Technology that examines this issue and provides some insight into why the surface roughness may affect the growth and stability of oxide layers on steels exposed to liquid lead-bismuth ${ }^{\text {viii }}$. According to the study, surface roughness may lead to local stress concentrations in the oxide layer and/or weaken the interface between the oxide and the substrate material, possibly causing the oxide to crack or detach from the underlying steel, exposing it to the liquid metal and accelerating corrosion degradation. While the Kondo, et al. study focused mainly on the convex and dented parts of the oxide in the rough sample compared to a smooth surface, this work intends to examine a more complete spectrum of practical surface roughness parameters and the associated trends in oxide scale formation and adherence to the substrate. 
The other surface modification technique in this experiment involved mechanically altering the surface of the steel by repetitively impinging it with small steel shots at high velocities, creating uniform compressive stresses at the surface. This process, known as shot peening, is widely used in aerospace and automobile industries. Shot-peening is also commonly used in the nuclear industry to prevent stress corrosion cracking in steam generator tubes ${ }^{\mathrm{ix}}$. A direct result of shot peening is a fine-grained microstructure in the surface region. The process generally results in increased resistance to fatigue failures, stress corrosion cracking, \& cavitation as well as improved intergranular corrosion performance ${ }^{\mathrm{x}}$.

\section{Corrosion Experiments}

\section{III.1 DELTA Loop Test 1}

The goal of this study was to determine the corrosion effects of LBE on three ferriticmartensitic steels with different $\mathrm{Cr}$ and other elemental contents with the objective of understanding oxide development in materials suitable for application in a lead-cooled reactor. The experiment was carried out at a relatively low temperature $\left(460^{\circ} \mathrm{C}\right.$, less than the operating temperature of proposed LFRs) in comparison to the other studies.

\section{III.1.1 Materials}

The candidate ferritic-martensitic steels investigated in this experiment were HCM12A, T22, and 9Cr-2WVTa, whose compositions are found below in Table I.

Table I - Alloy Compositions for DELTA Loop Test I by wt\% (balance Fe)

\begin{tabular}{|c|c|c|c|c|c|c|c|c|c|c|}
\hline Steel & $\mathrm{Cr}$ & $\mathrm{W}$ & $\mathrm{V}$ & $\mathrm{Mo}$ & $\mathrm{Cu}$ & $\mathrm{C}$ & $\mathrm{Si}$ & $\mathrm{Mn}$ & $\mathrm{Ni}$ & $\mathrm{Ta}$ \\
\hline HCM12A & $\mathbf{1 1 . 2 8}$ & 1.83 & 0.21 & 0.34 & 1.03 & 0.11 & 0.26 & .67 & .39 & -- \\
\hline T22 & $\mathbf{2 . 2 5}$ & -- & .005 & 0.94 & 0.23 & 0.11 & 0.22 & .42 & .19 & -- \\
\hline 9Cr-2WVTa & $\mathbf{8 . 9 0}$ & 2.01 & 0.23 & -- & .03 & 0.11 & .21 & .44 & -- & .06 \\
\hline
\end{tabular}

Others : HCM12A- .015P, .005S, .007B, .08Nb; T22- .006P, .018Al; 9Cr- .015P, .008S $.022 \mathrm{~N}$

HCM12A is a ferritic-martensitic steel designed for high-temperature fossil boiler components that is being evaluated for reactor applications. It contains the highest chromium content of the three materials tested. T22, which is a ferritic-martensitic steel typically used for lower temperature heat exchanger components, contains the lowest $\mathrm{Cr}$ content of the three materials tested. 9Cr-2WVTa is an experimental ferritic-martensitic stainless steel developed as a "low-activation" steel for fusion applications which contains the refractory element tantalum and no nickel or molybdenum.

The steel specimens for this research were prepared in the form of precisely machined $8 \times 35 \times 1 \mathrm{~mm}$ coupons. These specimens had an average surface finish of 32 micro-inches which is the equivalent of a rough polish attained by 60 grit $\mathrm{SiC}$ paper. 


\section{III.1.2 Experimental Conditions}

The test was carried out in the Los Alamos National Laboratories LBE DELTA (DEvelopment of Lead-Bismuth Target Applications) Loop ${ }^{\mathrm{xi}}$ (Figure 1). The temperature at the test section of the loop for this test was $460^{\circ} \mathrm{C}$. The loop has a flow velocity of $2 \mathrm{~m} / \mathrm{s}$ and oxygen sensors are used to maintain an oxygen concentration of $1 \times 10^{-6} \mathrm{wt} \%$. HCM12A and T22 were tested for 333, 666, and 1000 hours. The 9Cr-2WVTA was tested for only 666 and 1000 hours.

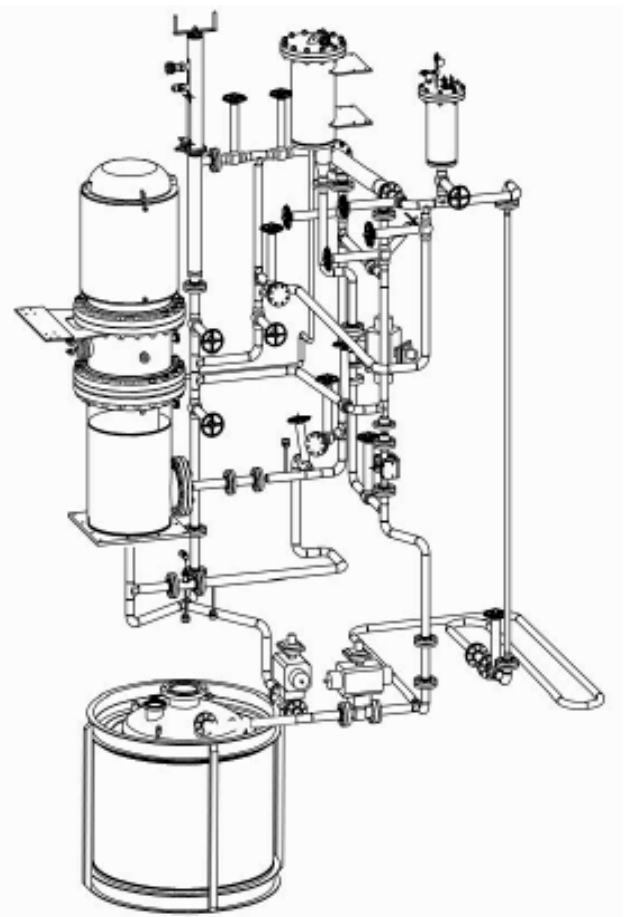

Figure 1- LANL's Lead-Bismuth Eutectic DELTA Loop.

Post-test sample preparation involved cleaning, cutting, and mounting the samples for SEM and EDS analysis. The as-received samples were cut into smaller pieces using a low speed diamond saw. To better observe the corrosion layer in plan view, a small piece of each specimen was placed in a $180^{\circ} \mathrm{C}$ mineral oil bath and gently swabbed to remove excess $\mathrm{Pb}$. Additional pieces of the specimens were mounted with a mounting press and subsequently polished with a wet grinder using 600,800 , and 1200 grit $\mathrm{SiC}$ paper and colloidal silica suspension for cross section SEM analysis.

\section{III.1.3 Results}

For a detailed identification of structures, the samples were viewed with a scanning electron microscope (SEM) at magnifications ranging from 200x to 10000x. Energy dispersive x-ray spectroscopy (EDS) of the samples was used determine the composition of various features as well as to perform line scans of cross section of the corrosion product. EDS information is obtained via line scan and is plotted to see how the composition changes with depth of the oxidation layer.

In general, we see results consistent with those of many others for oxide layer composition. There is an outer porous layer comprised mainly of iron and oxygen followed by a thinner 
and denser chromium-rich oxide layer. This observation is consistent with previous research findings that this $(\mathrm{Fe}, \mathrm{Cr})_{3} \mathrm{O}_{4}$ spinel layer protects the sample from a dissolution attack ${ }^{5, x x, x x i v}$.

\section{HCM12A}

The HCM12A samples present a good example of the duplex oxide structure. The thickness after 333 hours was $\sim 9$ microns, which did not change much for 666 and 1000 hours. The outer layer was $\sim 6$ microns and the inner layer $\sim 3$ microns. The EDS line scan suggests that the outer layer is an iron oxide $\left(\mathrm{Fe}_{3} \mathrm{O}_{4}\right.$, magnetite) and the inner layer is an iron and chromium spinel $(\mathrm{Fe}, \mathrm{Cr})_{3} \mathrm{O}_{4}$ (See Figure 2). There is some LBE contained within the magnetite layer, but is not seen in the spinel.
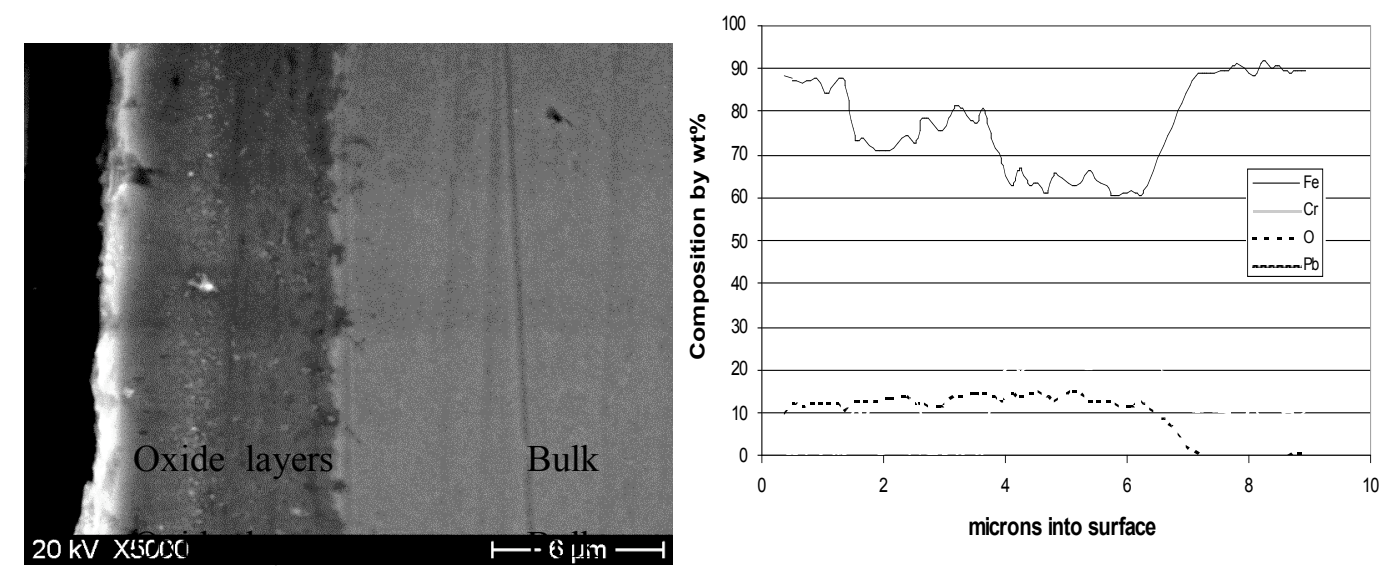

Figure 2- SEM image of $\mathrm{HCM12A}$ at $460^{\circ} \mathrm{C}$ after 1000 hours and corresponding EDS linescan.

T22

The T22 samples showed similar results to HCM12A for 333 hours, but a very different phenomenon after 666 and 1000 hours. The oxide layer for 333 hours was $\sim 9-12$ microns and again the inner layer was $\sim 3$ microns thick and was similar in appearance to the HCM12A samples. After 666 and 1000 hours however, Figure 3 shows the severe dissolution attack of the surface and liquid metal penetration along the grain boundaries.

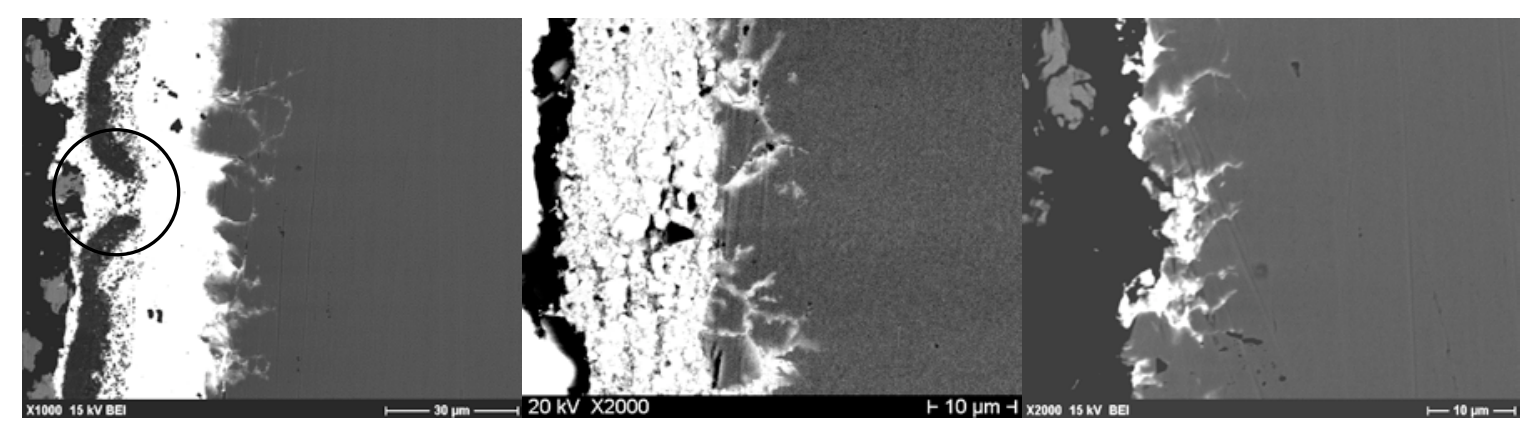

Figure 3- SEM image of $T 22$ at $460^{\circ} \mathrm{C}$ after $666 \mathrm{hrs}$ showing (left to right) $\mathrm{LBE}$ penetration below oxide layer, liquid metal penetration along grain boundaries, and bulk dissolution,.

The LBE penetrated beneath the oxide layer that formed on the surface of the sample. This poor performance may be attributed to the lower Cr content of the T22 samples, suggesting some minimum $\mathrm{Cr}$ content necessary for application of steels in higher temperature LBE environments. 


\section{Cr-2WVTa}

The results for the $9 \mathrm{Cr}$ steel are similar to those of the HCM12A but with a thinner oxide layer ( $\sim 8$ microns, $\sim 2-3$ micron inner layer). The oxide also appears to be less porous than HCM12A, but there is still some LBE present in the magnetite layer (Figure 4).
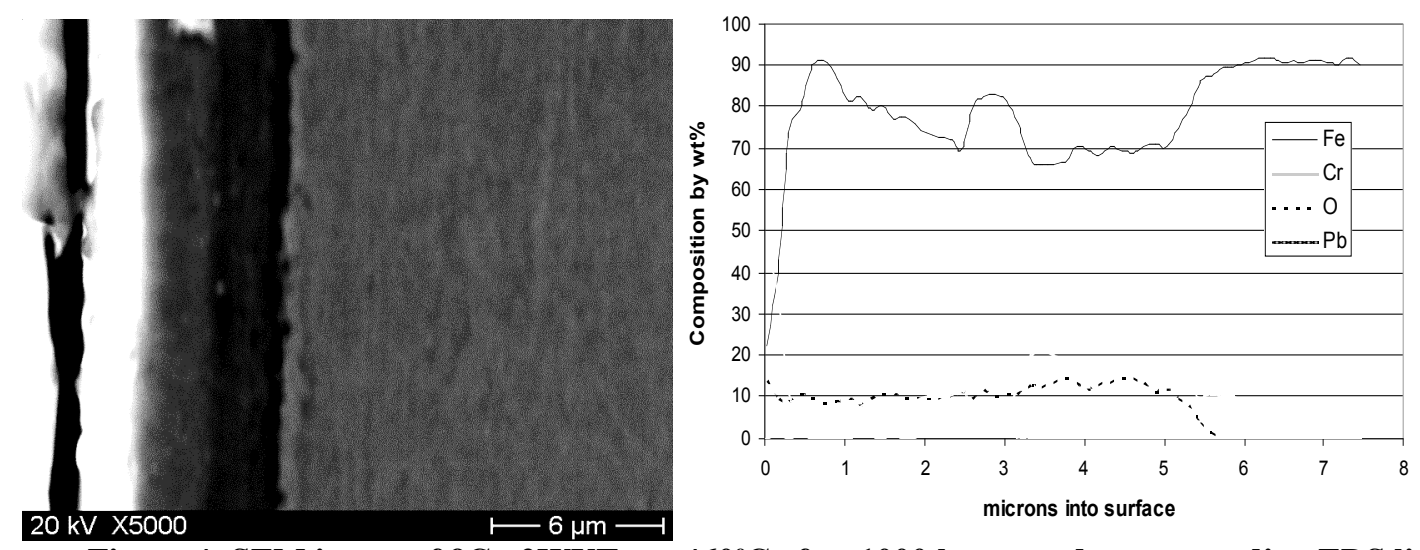

Figure 4- SEM image of $9 \mathrm{Cr}-2 \mathrm{WVTa}$ at $460^{\circ} \mathrm{C}$ after 1000 hours and corresponding EDS linescan.

The results for this sample are significant in that despite lower $\mathrm{Cr}$ content than the HCM12A (8.9\% compared to $11.28 \%$ ), the $9 \mathrm{Cr}-2 \mathrm{WVT}$ a may shows a slower oxide growth rate. This interesting result may be attributed to the Ta content, however further studies are necessary for confirmation of the corrosion effects of the differences in composition of the steels.

\section{Scratch Testing}

A scratch tester was used to perform a qualitative analysis of the adhesion of the corrosion products to the underlying steel. For this, a diamond-tip stylus is slowly dragged over the surface of the specimens using increasing mass. The point of oxide delamination is then determined through microscopy and compared to the other specimens. The scratch test allowed for a comparison of adhesion strength of the oxides. The performance of the oxide layers, as determined by the minimum load applied to the stylus required to produce oxide delamination from the substrate, was 9Cr-2WVTa strongest, followed by HCM12A, and the weakest was T22. This suggests that the strength of the oxide layer may be related to porosity of the oxide scale, as the $9 \mathrm{Cr}$ oxide scale appeared to be the least porous oxide of the three. An example of oxide delamination as seen via optical microscopy is shown below in Figure 5. 


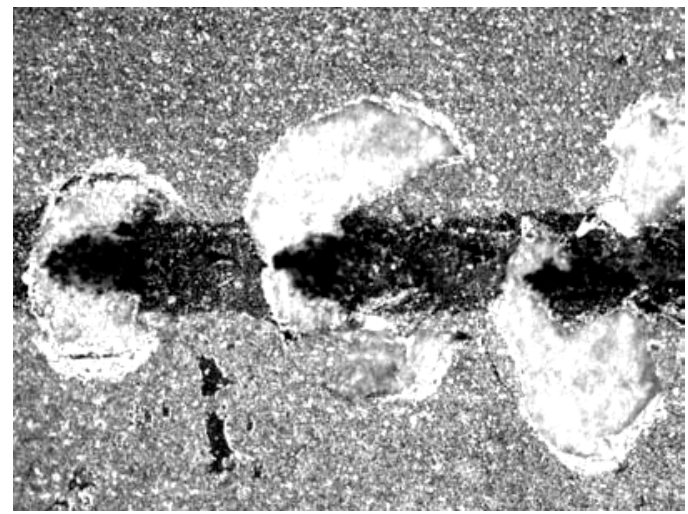

Figure 5- Optical microscopy of the delamination of oxide film from the surface of a 1000 hour HCM12A $460^{\circ} \mathrm{C}$ corrosion sample from application of a load in a scratch testing machine

\section{III.1.4 Summary}

The ferritic steels HCM12A, T22, and 9Cr-2WVTa were exposed in an LBE corrosion loop at $460^{\circ} \mathrm{C}$ for up to 1000 hours under conditions that should provide for the formation of an oxide layer to protect against liquid metal penetration and dissolution attack. Samples exhibited a duplex oxide structure comprised of an outer magnetite layer and an inner spinel layer, with the oxide thickness dependent on the alloy tested. The two alloys HCM12A and 9Cr-2WVTa, which did form a protective oxide and prevent more severe corrosion by the liquid metal, are suitable for further research for application in LBE environments. In this test the 9Cr-2WVTa sample had the thinner and denser oxide layers than the other samples, suggesting a better corrosion resistance under these conditions. Meanwhile, the poor performance T22 exhibited even in short term tests indicates that ferritic-martensitic alloys with a low amount of $\mathrm{Cr}$ may be prone to dissolution and liquid metal attack after extended exposure to the LBE and are undesirable for application in Lead-Cooled Reactors. Since there was not much increase in oxide thickness between the initial 333 hours and 1000 hours it may be necessary to decrease the loop exposure time to examine the initial oxidation kinetics.

\section{III.2 DELTA Loop Test 2}

The purpose of this experiment was to again assess the corrosion performance of three candidate alloys-- this time at a higher temperature of $530^{\circ} \mathrm{C}--$ but also to evaluate several plasma-assisted elemental surface treatments for corrosion protection.

\section{III.2.1 Materials}

The three candidate alloys under consideration in this experiment include: NF616, a nominal 9\% chromium steel; HCM12A, a nominal 12\% chromium steel (same as in Test 1); and a 9Cr oxide dispersion strengthened (ODS) steel. NF616 and HCM12A are third-generation ferritic martensitic steels being considered for LFR applications due to their favorable mechanical and nuclear properties ${ }^{\mathrm{xii}}$. The ODS steel exhibits remarkable strength even at temperatures as high as $750^{\circ} \mathrm{C}$ due to the presence of a fine dispersion of nanometer sized clusters of yttriumtitanium-oxide and a resulting grain structure that is much finer than that of the other steels. 
The steel specimens for this research were prepared in the form of precisely machined $8 \times 35 \times 1 \mathrm{~mm}$ coupons. Before surface modification and exposure to molten lead-bismuth alloy, samples were polished with silicon-carbide grinding papers of progressively finer grit sizes and a colloidal silica suspension size to obtain a mirror finish. Compositions of the steels investigated in this research are listed in Table II:

Table II - Alloy composition for DELTA Loop Test 2 by wt\%, balance Fe

\begin{tabular}{|c|c|c|c|c|c|c|c|c|c|c|c|c|c|c|c|}
\hline & $\mathrm{Cr}$ & $\mathrm{Ni}$ & Mo & Mn & $\mathbf{W}$ & Si & V & $\mathrm{Nb}$ & $\mathrm{Ti}$ & C & 0 & $\mathbf{N}$ & $\mathrm{Cu}$ & $\mathbf{Y}$ & $\mathrm{Y}_{2} \mathrm{O}_{3}$ \\
\hline HCM12A & 10.83 & 0.39 & 0.30 & 0.64 & 1.89 & 0.27 & 0.19 & .054 & - & 0.11 & - & .063 & 1.02 & - & - \\
\hline NF616 & 8.82 & 0.174 & 0.468 & 0.45 & 1.87 & 0.102 & 0.194 & 0.064 & - & 0.109 & .0042 & & - & - & - \\
\hline ODS & 8.67 & 0.06 & - & 0.05 & 1.95 & 0.05 & - & - & 0.23 & 0.14 & 0.14 & .017 & - & 0.28 & 0.35 \\
\hline
\end{tabular}

\section{III.2.2 Surface Treatments}

Select samples of the steel were chemically surface modified with either oxygen, yttrium, tantalum, or silicon. The species used for surface treatments were chosen based on several factors including chemical and physical properties as well as the species' proven abilities to mitigate corrosion in other studies. Oxygen is a natural choice because the implanted oxygen is expected to provide a dense protective oxide film and allows control over the surface oxygen partial pressure. Silicon has been included due to good LBE corrosion results when used as an alloying agent in some Russian steels ${ }^{\mathrm{ii}}$ as well as some current MIT studies ${ }^{\mathrm{xiii}}$. However, Si can tend to exacerbate stress corrosion cracking and irradiation embrittlement under heavy irradiation when used as an alloying agent ${ }^{\mathrm{xiv}}$ so a surface application could provide a corrosion benefit without this detriment. Tantalum is a refractory metal, with a very high melting point and little or no corrosion or solubility in lead, but has a high capture cross section which also lends it well to surface application rather than alloying. Finally, yttrium which has an enormous affinity to react with oxygen to form a stable oxide has shown promising results in University of Wisconsin studies on corrosion in supercritical water environment ${ }^{\mathrm{xv}}$. These ion-based surface treatments were carried out at near-room temperature; as a result there is no thermally-induced microstructural degradation in the base alloy. The depth of the modified region in all cases is in the sub-micron range (See Figure 6). For comparison purposes, mirror polished control samples of untreated steels were also subjected to corrosion testing under identical conditions.

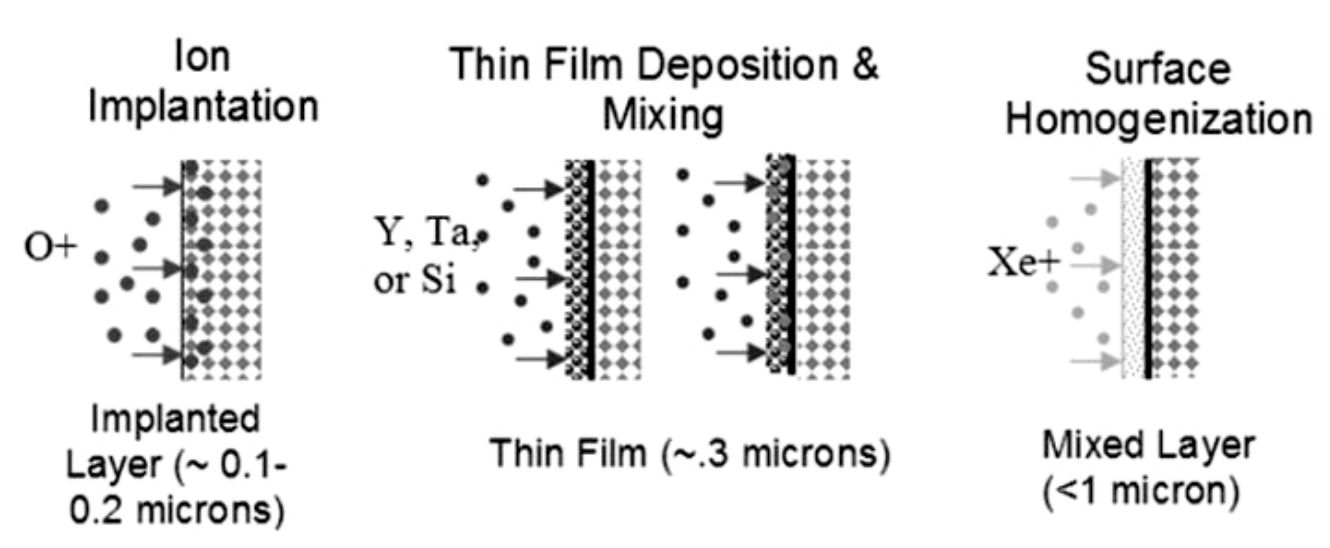

Figure 6- Schematic illustration of surface modification approaches. 


\section{III.2.3 Experimental Conditions}

Exposure of these alloys to molten lead-bismuth eutectic environment at $530^{\circ} \mathrm{C}$ was carried out in the DELTA Loop at the Los Alamos National Laboratory. The molten alloy flow velocity in the loop was $1.2 \mathrm{~m} / \mathrm{s}$ and oxygen sensors were used to measure and maintain an oxygen concentration at about $1 \times 10^{-6} \mathrm{wt} \%$. Samples were exposed for 200, 400, and 600 hours to study early stages of oxide formation and growth.

Characterization of exposed samples was carried out by Scanning Electron Microscopy (SEM) with both secondary and backscattered electron imaging (SEI, BEI). Examination was made both in surface plan view and in cross-section and analyzed with energy dispersive $\mathrm{x}$-ray spectroscopy (EDS) in the form of elemental composition maps, line scans, and surface spectra. X-ray photoelectron spectroscopy (XPS) and Rutherford backscatter spectroscopy (RBS) were also employed to better characterize the materials by obtaining information about oxidation states, composition, and thicknesses of the thin surface layers.

\section{III.2.4 Control Samples}

To examine the effects of the elemental surface treatment the performance of the untreated materials must be first characterized.

\section{HCM12A Control}

The surface and cross-section SEM/EDS of the HCM12A samples show the early formation of iron oxide $\left(\mathrm{Fe}_{3} \mathrm{O}_{4}\right.$, magnetite) grains on the surface, which are eventually carried away by the LBE to reveal a much smoother underlying $\mathrm{Cr}$-rich oxide layer $\left((\mathrm{Fe}, \mathrm{Cr})_{3} \mathrm{O}_{4}\right)$ and a diffusion zone underneath (See Figure 7-8). By contrast, the same alloy tested at $460^{\circ} \mathrm{C}$ in previous experiments (see Sec. III.1) had the outer magnetite layer still intact even after 1000 hours, with a Fe-Cr spinel layer underneath. Hence the increased temperature, which corresponds with faster diffusion rates, decreases the amount of time it takes to form a uniform protective Cr-rich spinel and to remove the outer magnetite. The thickness of the spinel layer remains relatively constant after 200 hours at $530^{\circ} \mathrm{C}$, although the thickness of the diffusion layer continues to increase.
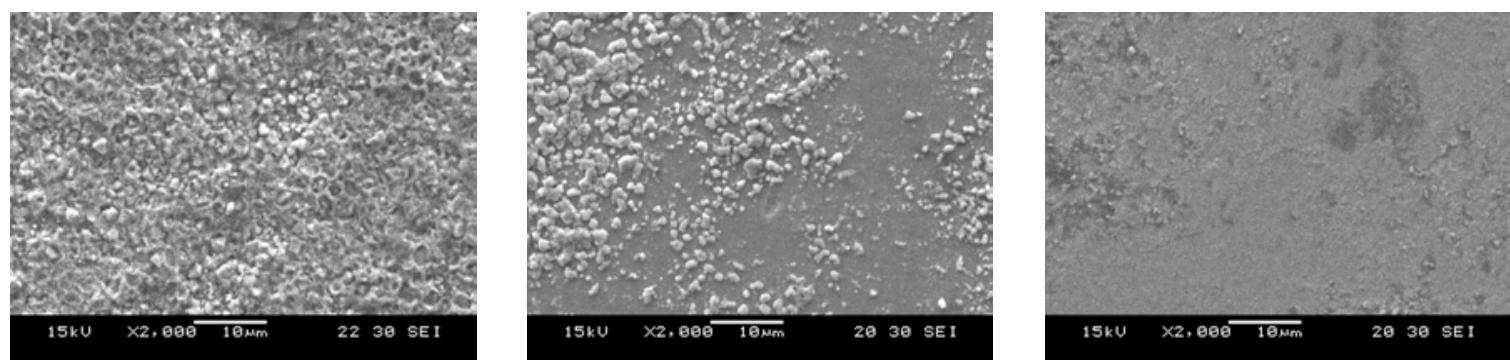

Figure 7- Secondary SEM surface micrographs of 200,400 , and 600 hour exposed $\left(530^{\circ} \mathrm{C}\right) \mathrm{HCM12A}$ samples showing how eventual removal of Fe-oxide particles reveals protective $\mathrm{Cr}$-rich oxide layer. 

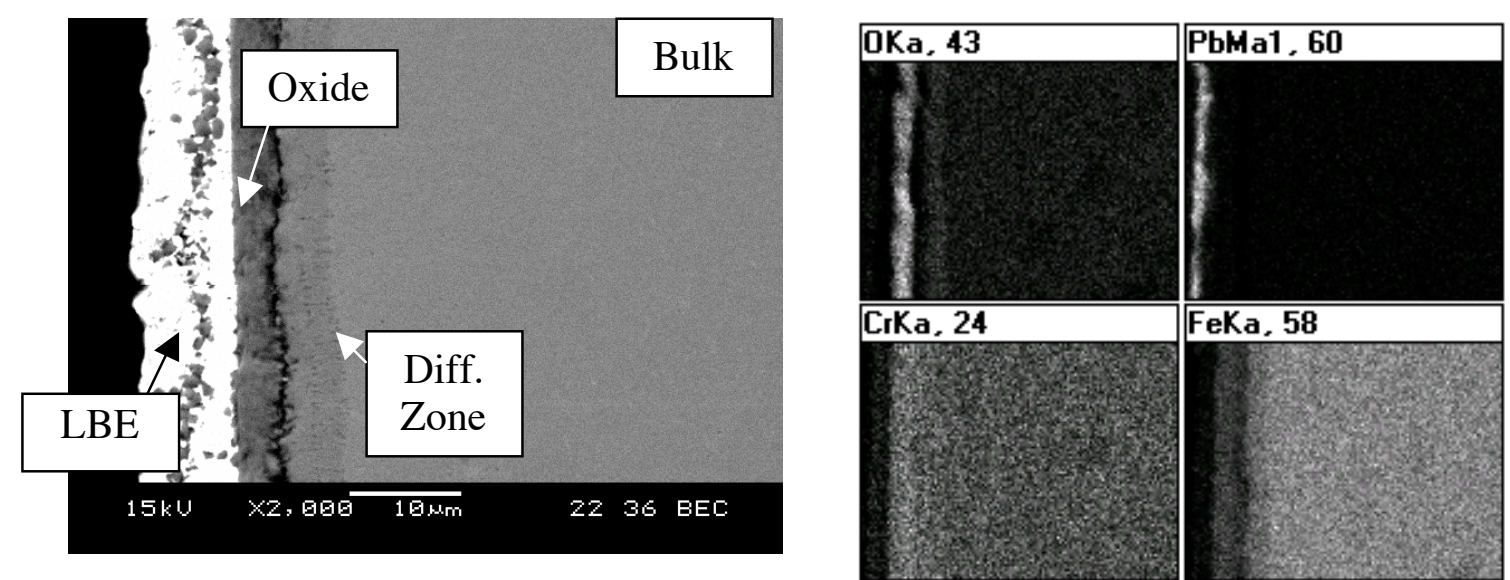

Figure 8- HCM12A samples show Cr-rich oxide and diffusion zone in a backscatter cross-section SEM image (left) after 400 hours of exposure and an EDS map (right) after 600 hours at $530^{\circ} \mathrm{C}$.

\section{NF616 Control}

Surface SEM images of NF616 show a similar trend of Fe-oxide particle removal to reveal a smoother (though less so than HCM12A) surface after 600 hours. However the cross section images display a thicker oxide and a much thinner diffusion zone (see Figure 9-10). The diffusion zone is not visible at all after a 200hr exposure (not shown), For NF616, the outer layer of Cr-rich spinel grew slightly while the inner diffusion zone stayed constant after 400 hours. The differences in oxidation mechanism may be related to the smaller amount of $\mathrm{Cr}$ relative to $\mathrm{HCM} 12 \mathrm{~A}$.
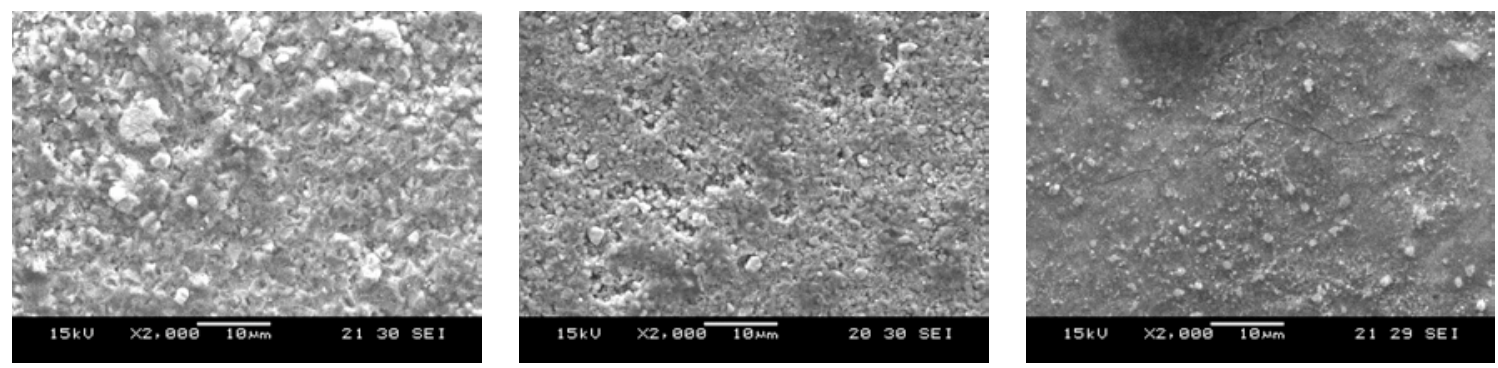

Figure 9 - Secondary SEM surface micrographs of 200, 400, and 600 hour exposed $\left(530^{\circ} \mathrm{C}\right) \mathrm{NF616}$ samples again showing how eventual removal of Fe-oxide layer particles reveals protective $\mathrm{Cr}$-rich oxide layer. 


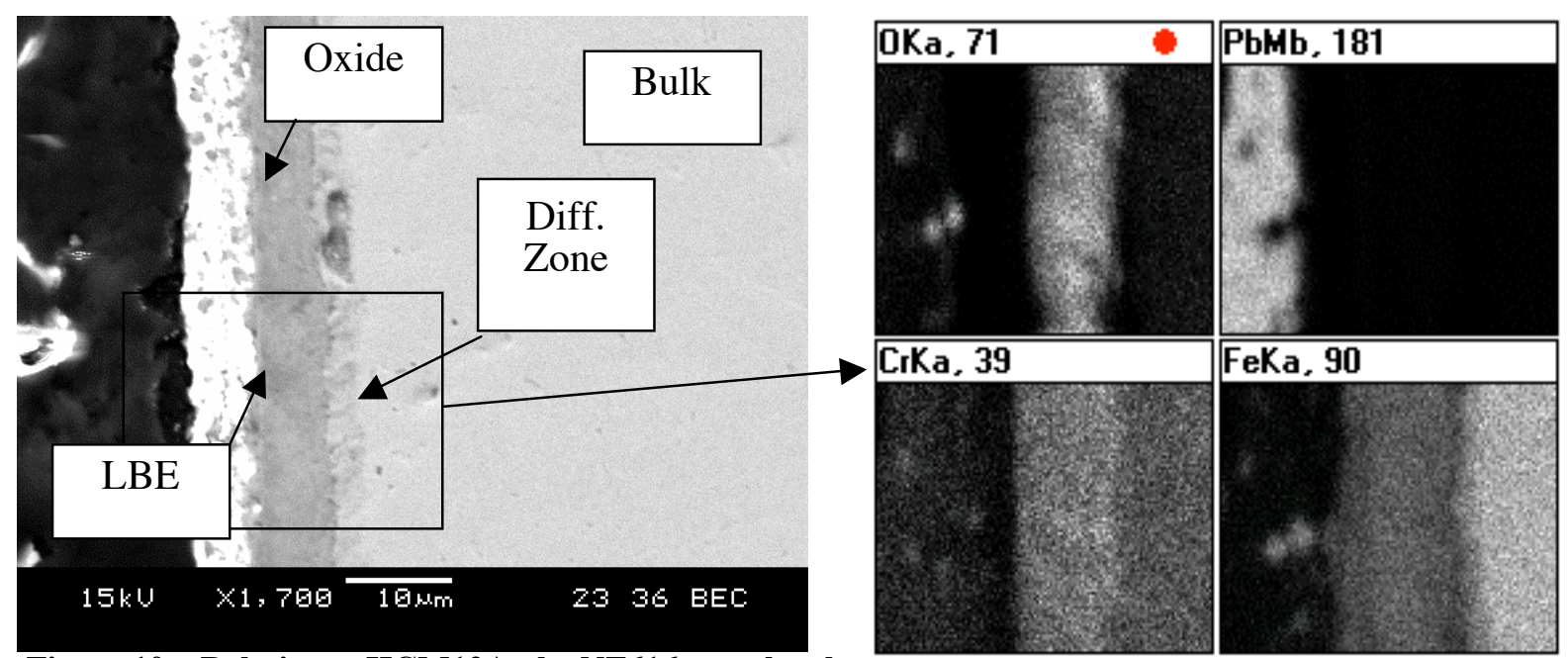

Figure 10 - Relative to HCM12A, the NF616 samples show a tnıcker Cr-rıcn oxıde layer $\alpha$ a tnınner diffusion zone in a backscatter cross-section SEM image (left) after 400hr of exposure and an EDS map (right) after $600 \mathrm{hr}$ at $530^{\circ} \mathrm{C}$.

\section{ODS Steel Control}

For the $9 \mathrm{Cr}$ - ODS steel, the magnetite has already been removed to reveal a very smooth surface after only 400 hours. ODS exhibits the reverse trend compared to NF616 in that the spinel is now much thinner while the diffusion zone is thicker (See

Figure 11-12). Although Cr content is similar to NF616, an increased removal rate of the outer oxide occurs on the much finer grained ODS steel.

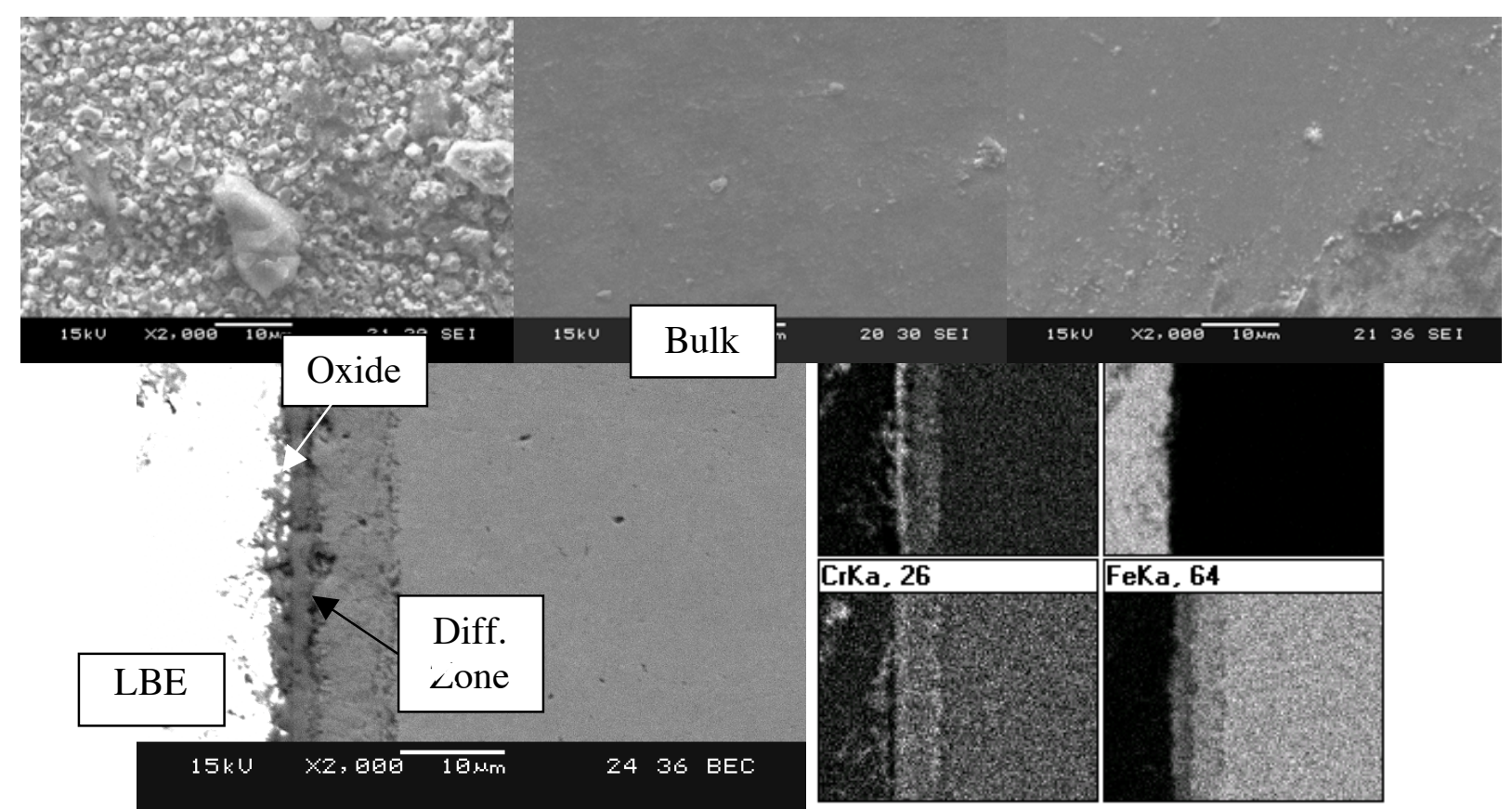

Figure 12 - Backscatter cross-section SEM image and EDS map of 600 hour ODS sample showing much thinner Cr-rich oxide but a thicker diffusion zone.

At short times, the steels formed a protective duplex oxide layer consisting of an outer magnetite $\left(\mathrm{Fe}_{3} \mathrm{O}_{4}\right)$ layer and an inner $\mathrm{Fe}-\mathrm{Cr}$ spinel $\left((\mathrm{Fe}, \mathrm{Cr})_{3} \mathrm{O}_{4}\right)$ layer which is sometimes accompanied by an $\mathrm{O}$-enriched and $\mathrm{Fe}$-depleted diffusion zone at the oxide-bulk 
interface. With time, the outer magnetite layer is removed by the melt and the underlying spinel layer serves to mitigate more catastrophic corrosion degradation such as dissolution and liquid metal attack along grain boundaries. Very thin oxides are not particularly protective in regards to loss of metal, as manifested by thick diffusion zones associated with them. The thickness of the oxide layers (magnetite plus spinel) and diffusion zone versus time are shown in

Table III:

Table III - Oxide Thicknesses in Microns vs. Time for $530^{\circ} \mathrm{C}$ LBE Exposure

\begin{tabular}{lccc|c} 
Alloy & Hours & Oxide Layers & Diff. Zone & Total \\
\hline \multirow{3}{*}{ HCM12A } & $\mathbf{2 0 0}$ & 4.46 & 2.98 & 7.44 \\
& $\mathbf{4 0 0}$ & 4.42 & 4.83 & 9.25 \\
& $\mathbf{6 0 0}$ & 4.93 & 5.21 & 10.14 \\
\hline \multirow{3}{*}{ NF616 } & $\mathbf{2 0 0}$ & 5.92 & 0.00 & 5.92 \\
& $\mathbf{4 0 0}$ & 6.66 & 3.70 & 10.36 \\
& $\mathbf{6 0 0}$ & 7.31 & 2.35 & 9.66 \\
\hline \multirow{2}{*}{ ODS } & $\mathbf{2 0 0}$ & 2.47 & 5.43 & 7.90 \\
& $\mathbf{4 0 0}$ & 4.61 & 5.92 & 10.53 \\
& $\mathbf{6 0 0}$ & 2.14 & 7.86 & 10.00
\end{tabular}

It is important to point out that these experiments are the first known observation of removal of the outer magnetite layer within such a short period of time. Models presented by Zhang and Li had predicted such a removal but not for much longer timeframes ${ }^{\mathrm{xi}}$. Therefore, a theoretical model based on the same framework used by Zhang and Li has been reworked and applied to these novel experimental results in attempt to explain differences in experimental data and to improve upon the predicative capabilities of existing models (See Sections IV-V).

\section{III.2.5 Plasma-Assisted Elemental Surface Treatments}

\section{Oxygen Implanted Samples}

The direct oxygen implantation is expected to provide a pre-oxidation condition in which a thin oxide will form prior to LBE exposure. One can see in Figure 13 below that there is a small pre-oxidation layer between the $\mathrm{Cr}$-rich oxide and the diffusion zone that is depleted in Fe. This oxide acts to control the amount of oxygen that reaches the surface and allows for a controlled growth of the oxide layer, thereby forming a denser, more uniform protective layer. 

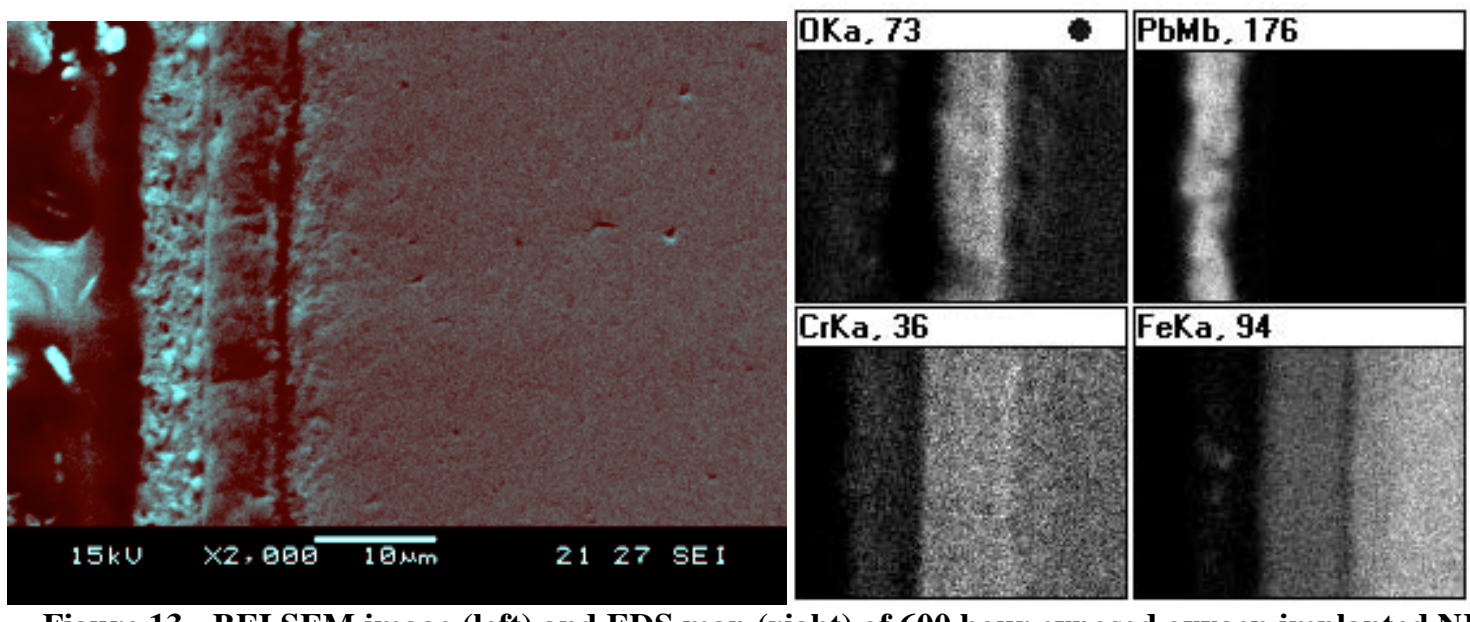

Figure 13- BEI SEM image (left) and EDS map (right) of 600 hour exposed oxygen implanted NF616 with Cr-rich intermediate oxide layer.

\section{Silicon, Tantalum, and Yttrium Treated Samples}

The $\mathrm{Si}$, Ta, or $\mathrm{Y}$-sputtered, $\mathrm{Xe}+$ bombarded samples were expected to form a thin layer of silica $(\mathrm{SiO} 2)$, tantala $\left(\mathrm{Ta}_{2} \mathrm{O}_{5}\right)$, or yttria $\left(\mathrm{Y}_{2} \mathrm{O}_{3}\right)$ at the surface to protect against any further corrosion. Upon SEM inspection (Figure 14-17) one can see that the treatments were quite effective in preventing a thick oxide from forming or a liquid metal attack.

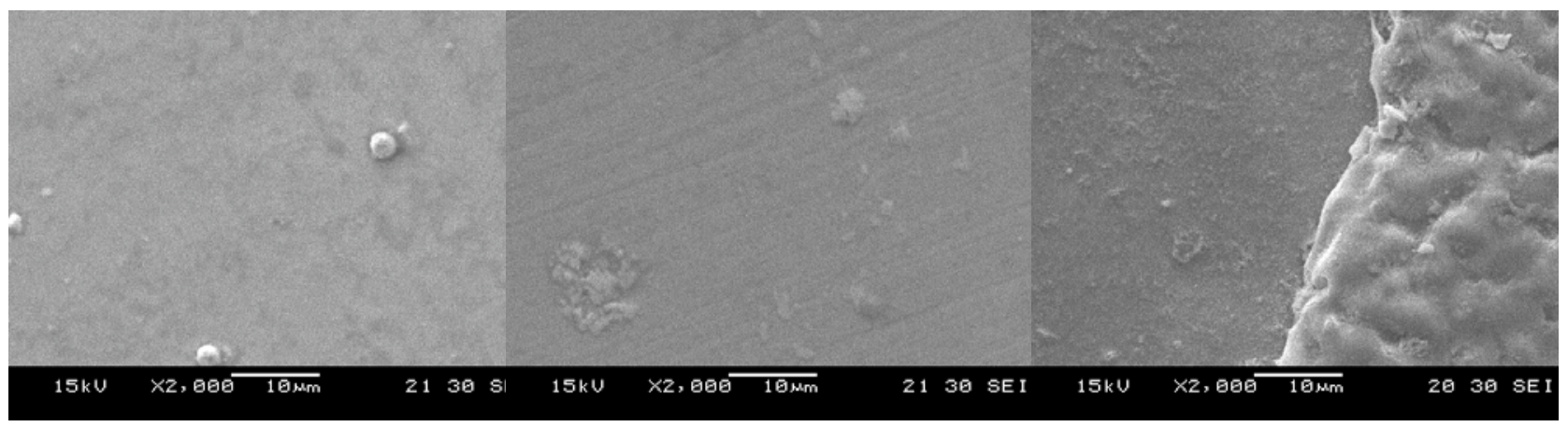

Figure 14- Plan view SEM of 600 hour Si, Ta, and Y-treated NF616 (from left).

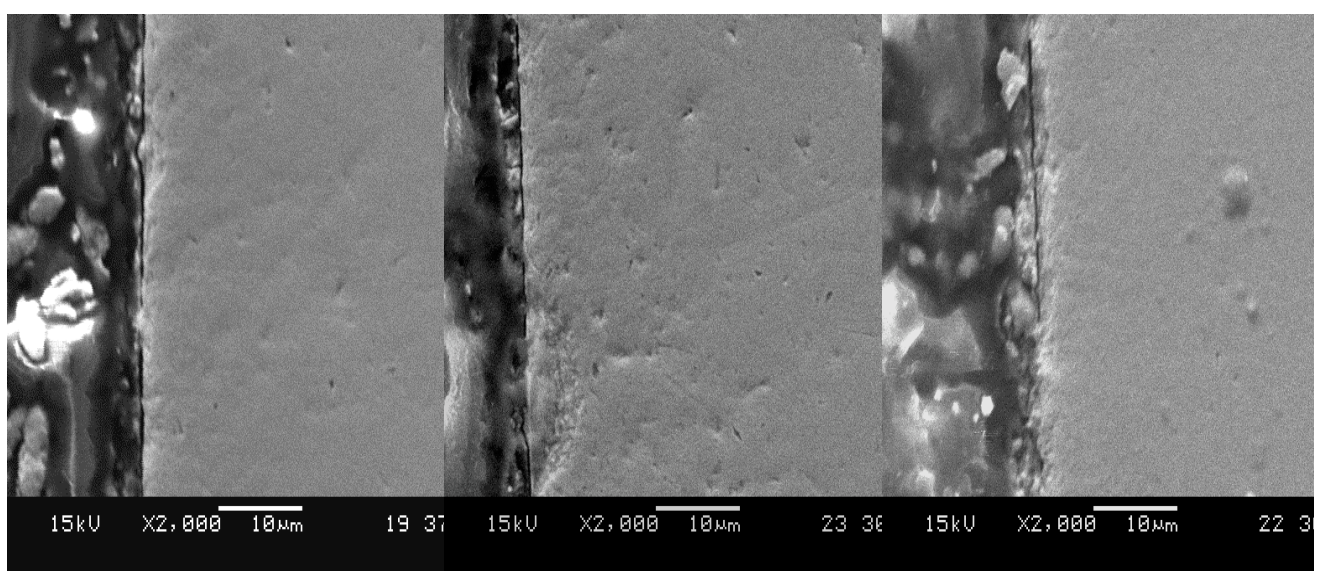

Figure 15- Cross-section view SEM of 600 hour Si, Ta, and Y-treated NF616 (from left).

The Y-treated sample had a large portion (See far right side of Figure 14) that was not protected due to the formation of an oxide layer between the yttrium and the bulk metal (as 
later determined by auger electron spectroscopy of an unexposed sample). Small islands of oxide formation that can be seen on the surface are actually formed during the treatment process, but may provide sites for the protective layer to break down during LBE exposure. Figure 16a shows a large oxide island growing around a pinhole in the Ta layer. Figure 16b suggests that even in the regions where an oxide was formed, likely due to a locally inadequate surface treatment application, the oxide structure is similar to that of the $\mathrm{O}+$ implanted samples, suggesting that the treatment may still provide some corrosion performance enhancement.
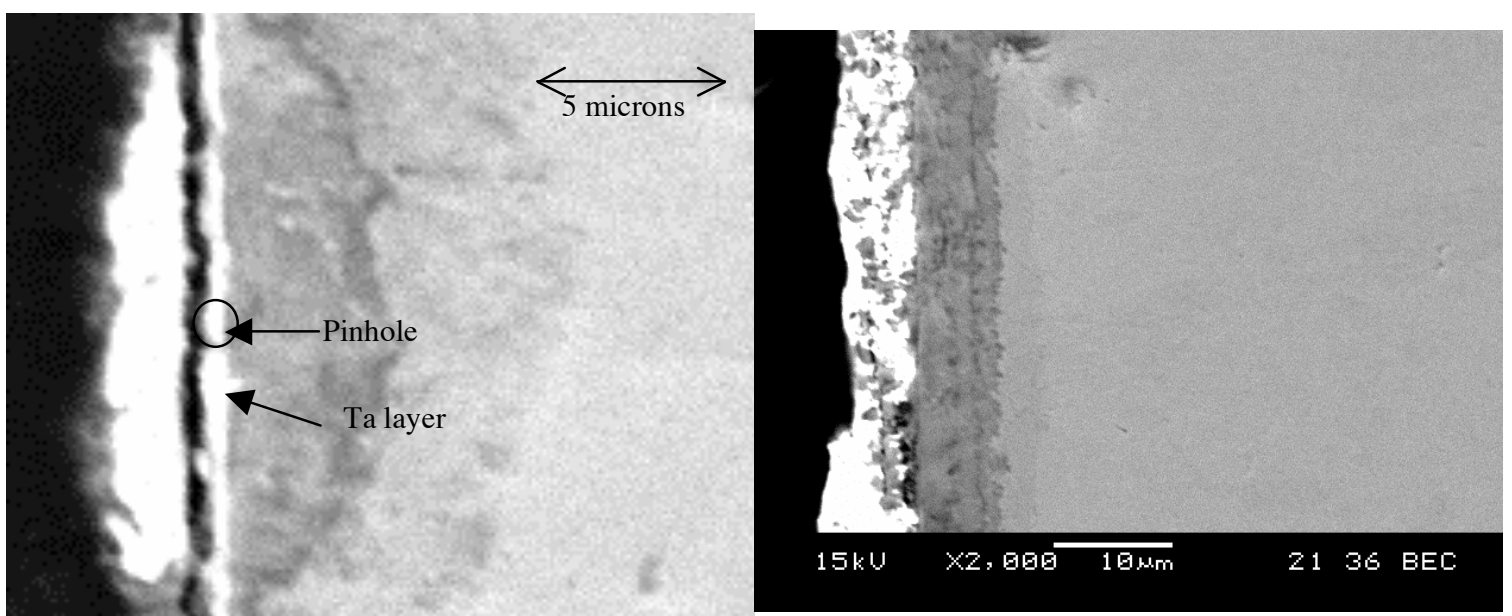

Figure 16- a) Pinhole defect in Ta surface treatment of 600 hour exposed NF616 causing local bulk oxidation b) Si-treated 600 hour exposed NF616 displaying similar structure to O+ implanted sample.

These observations indicate the importance of optimizing surface treatment procedures to minimize pin-holes and other defects. 


\section{XPS Analysis}

XPS (X-ray Photoelectron Spectroscopy) spectra of the surfaces of the Si-treated samples after 600 hours confirmed the presence of nearly pure silica $\left(\mathrm{SiO}_{2}\right)$ based on the oxidation states of the surface constituents (Figure 17). The small amount of $\mathrm{Fe}$ and $\mathrm{Cr}$ that is present is also oxidized.

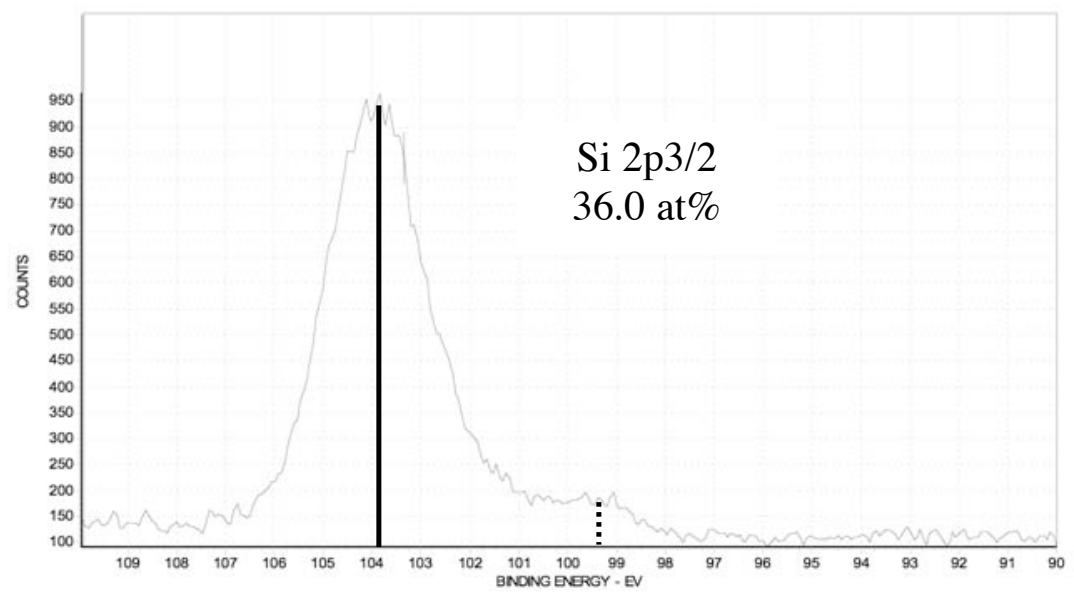

Figure 17- Silicon XPS spectrum for Sa-treated NF616 after 600 hours of exposure. The solid line indicates the oxidized state, and the dotted line is elemental $\mathrm{Si}$.

The XPS spectra for the 600 hour Ta-treated sample indicates $\mathrm{Ta}_{2} \mathrm{O}_{5}$ (tantala) formation at the surface. There is also an appreciable amount of elemental Ta left at the surface. The Ta appears to be using up any available oxygen because the $\mathrm{Fe}$ and $\mathrm{Cr}$ are present in mostly elemental form (Figure 18).

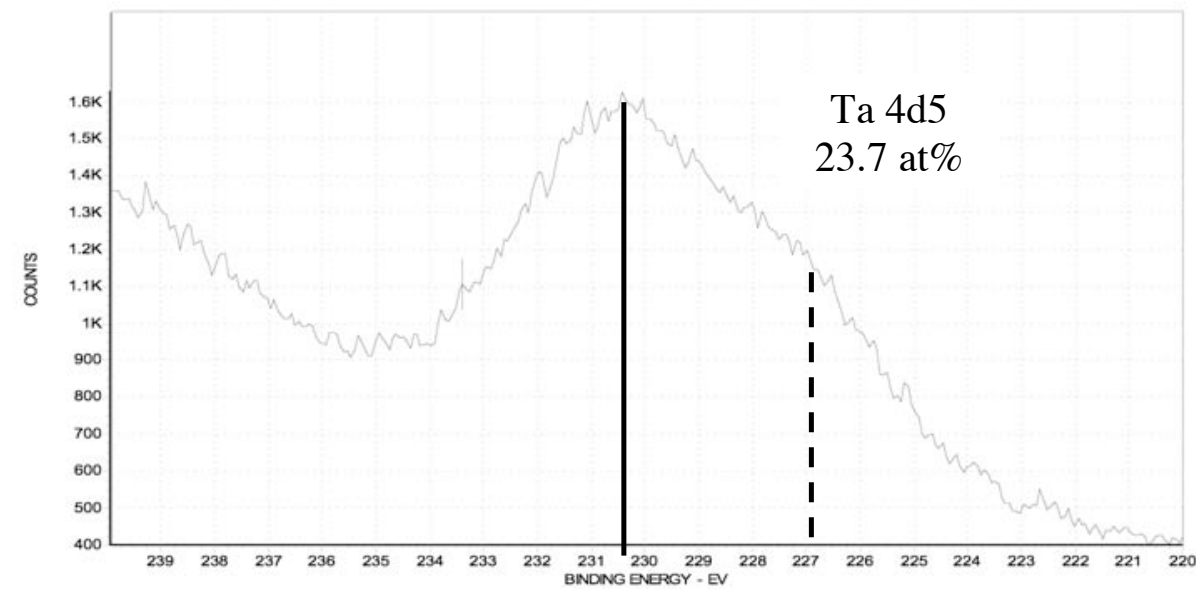

Figure 18- Tantalum XPS spectrum for Ta-treated NF616 after 600 hours of exposure. The solid lines indicate an oxidized state, and the dotted line is elemental Ta.

The 600 hour exposed Y-treated sample analyzed with XPS is also slightly difficult to extract clear information because the oxidized $\mathrm{Y}$ peak is very close to that of $\mathrm{Bi}$. Nearly all the $\mathrm{Y}$ is oxidized as $\mathrm{Y}_{2} \mathrm{O}_{3}$ (yttria) based on peak location (Figure 19). 


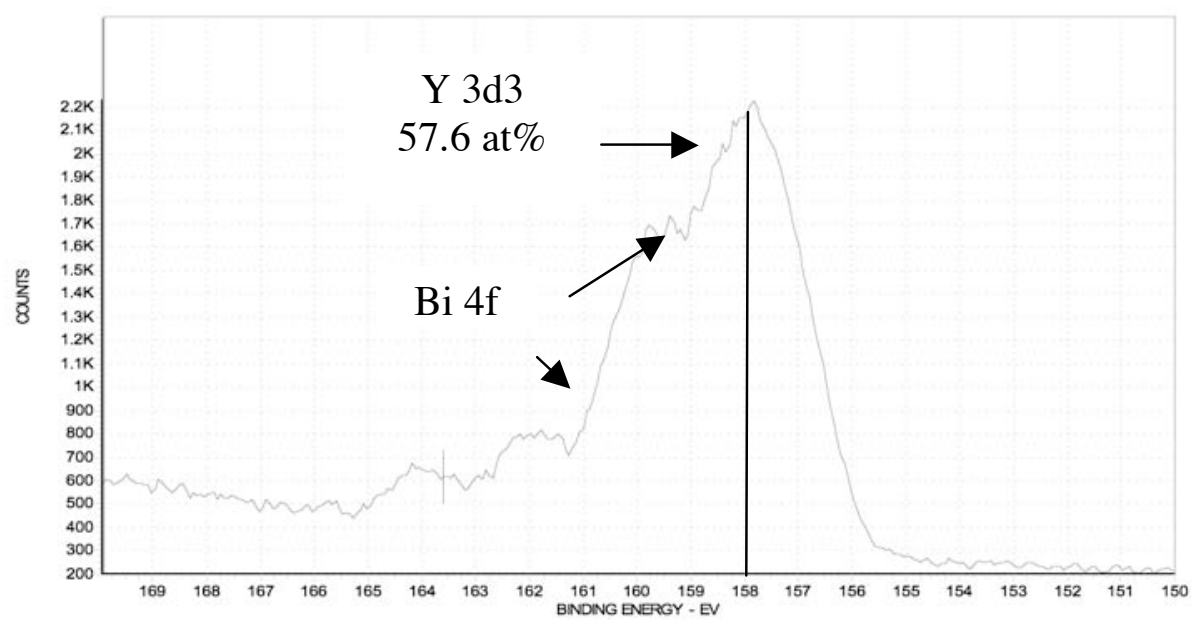

Figure 19 - Yttrium XPS spectrum for Y-treated NF616 after 600 hours of exposure. The solid line indicates an oxidized state.

\section{RBS Analysis}

RBS (Rutherford backscatter spectroscopy) can provide a model of the modified layer's composition and thickness. The analysis was done on the 200 hour exposed samples for a picture of what is present at early stages of exposure and to ensure that the modified layer is still in tact.

For the Si-treated sample, RBS indicates that the original Si-modified region is approximately 1000 Angstroms thick and at 200 hours some of the Si is still in elemental form (as opposed to the 600 hour sample which was determined to be completely oxidized) (See Figure 20).

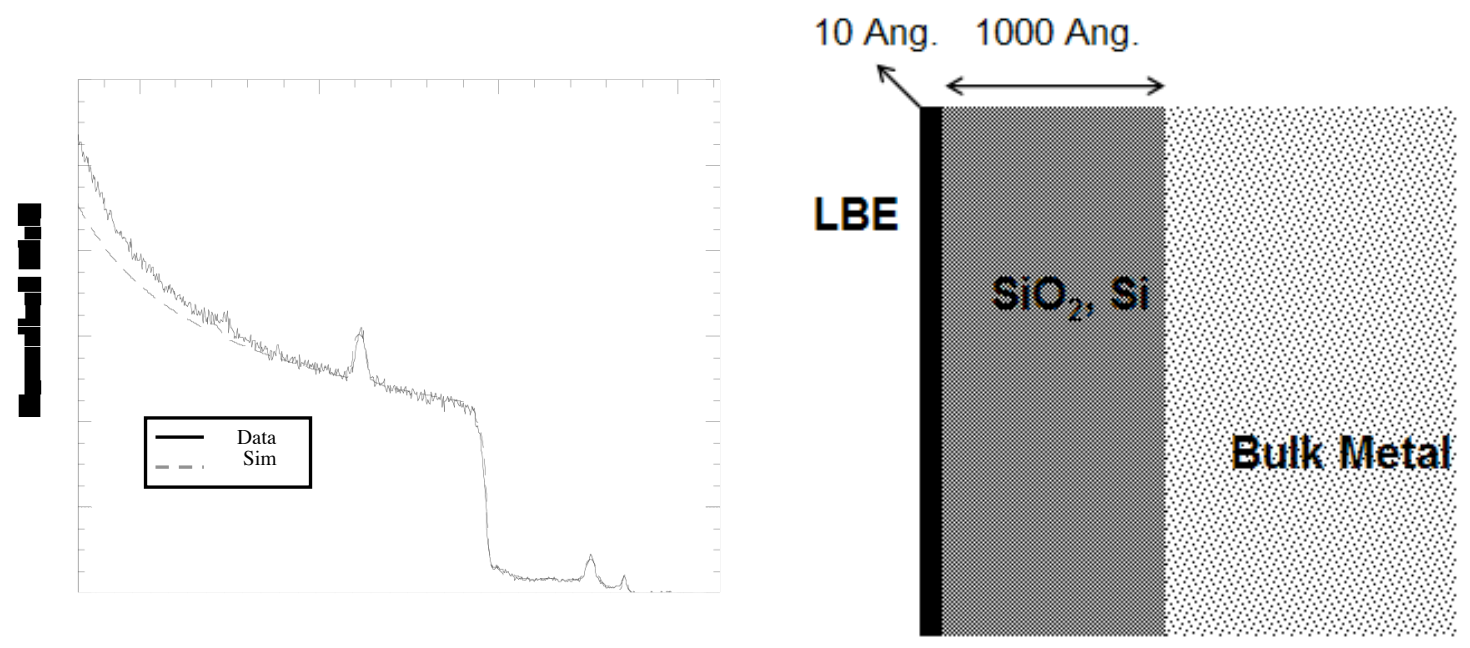

Figure 20- RBS raw and simulated spectra for Si-treated $200 \mathrm{hr}$ exposed sample with corresponding schematic.

RBS analysis of the 200 hour Ta-treated sample yields a 2500 Angstrom layer of Ta/Ta2O5 ( $80 \%$ decreasing to $20 \%$ Ta towards the bulk) is present that is thicker than the Si treatment and is followed by a thin (900 angstroms) Fe-Cr spinel layer (see Figure 21). 

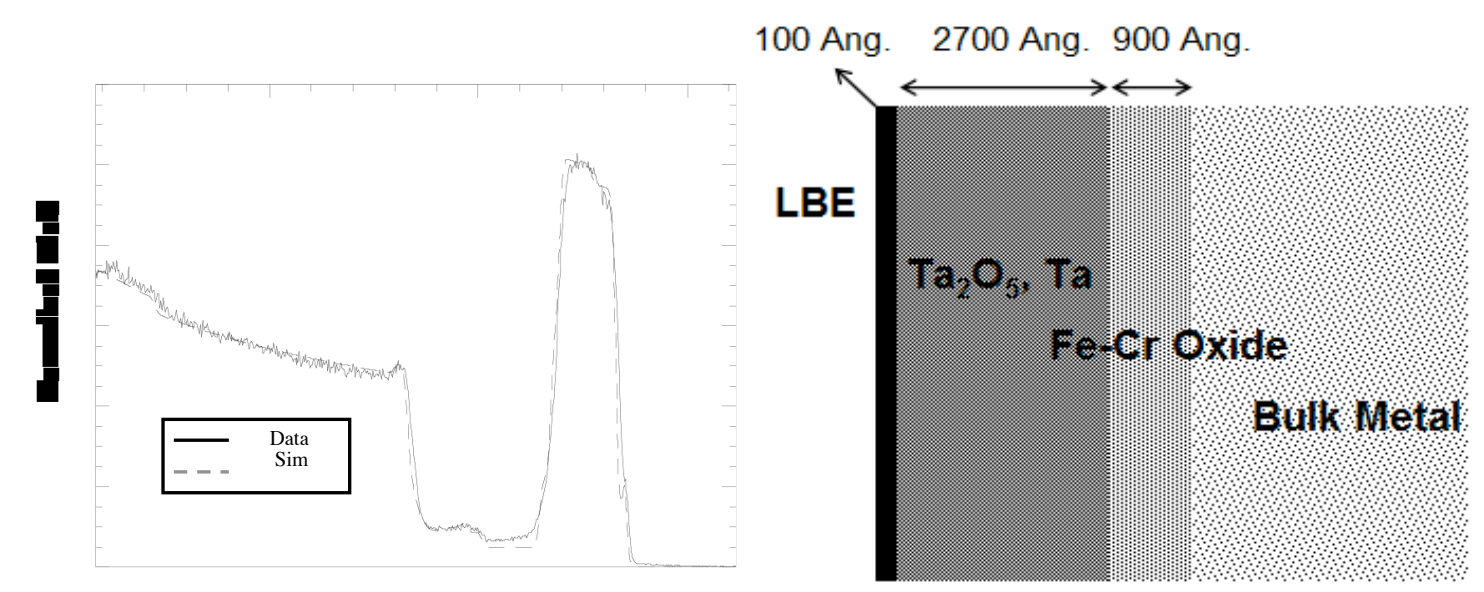

Figure 21- RBS raw and simulated spectra for Ta-treated 200hr HCM12A with corresponding schematic.

RBS on the Y-treated sample shows a 4100 angstrom total affected thickness with a smooth transition from mostly yttria on the outer surface to more $\mathrm{Fe}-\mathrm{Cr}$ oxide towards the bulk (Figure 22).
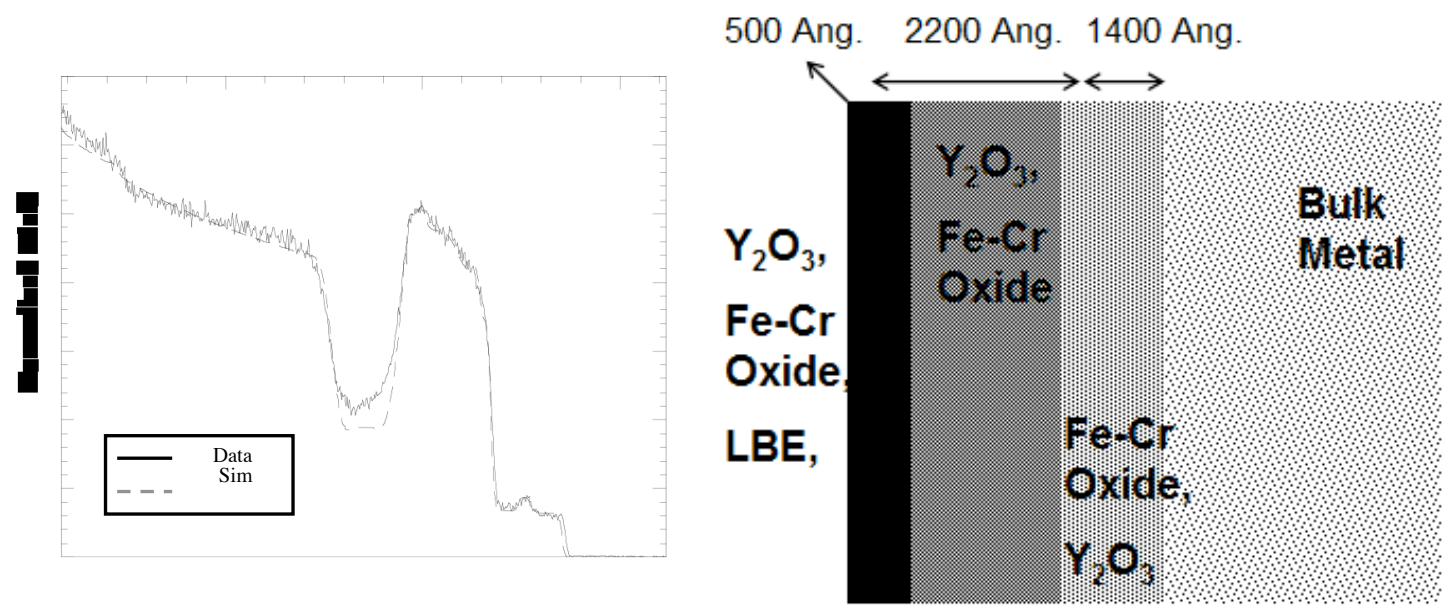

Figure 22 - RBS raw and simulated spectra for Y-treated 200hr exposed HCM12A with corresponding model.

\section{Summary}

Oxygen implantation forms an Fe-Cr oxide layer (either early in or prior to exposure i.e. preoxidation) which acts to control the oxygen transport at the surface and allows for the formation of a denser and more uniform oxide layer, which is desirable from the standpoint of long term corrosion performance. Properly applied, the Si and Ta treatments in particular have proven effective means to mitigate oxidation in $\mathrm{LBE}$ by forming $\mathrm{SiO}_{2}$ or $\mathrm{Ta}_{2} \mathrm{O}_{5}$ layer at the surface. The $\mathrm{Y}$ treatment, while also providing some protection, pre-forms an oxide layer during the surface treatment process in some regions, thereby reducing its effectiveness by providing a weakly adherent oxide that is not stable during further oxide growth. In all cases, careful uniform application of the deposited and implanted layer is required for protection. 


\section{III.3 DELTA Loop Test 3}

\section{III.3.1 Materials}

This experiment examined the effects of surface roughness and shot peening on the corrosion mechanisms of ferritic-martensitic steel in LBE at $535^{\circ} \mathrm{C}$. The candidate alloy chosen for this study was the same NF616 steel as Test 2 with composition listed previously in Table II (see Sec. III.2).

\section{III.3.2 Sample Modifications}

For the surface roughness study, an array of surface roughness from an as-machined condition to a mirror finish was used. Typical SEM micrographs of these surfaces before exposure to LBE are shown in Figure 23.

A

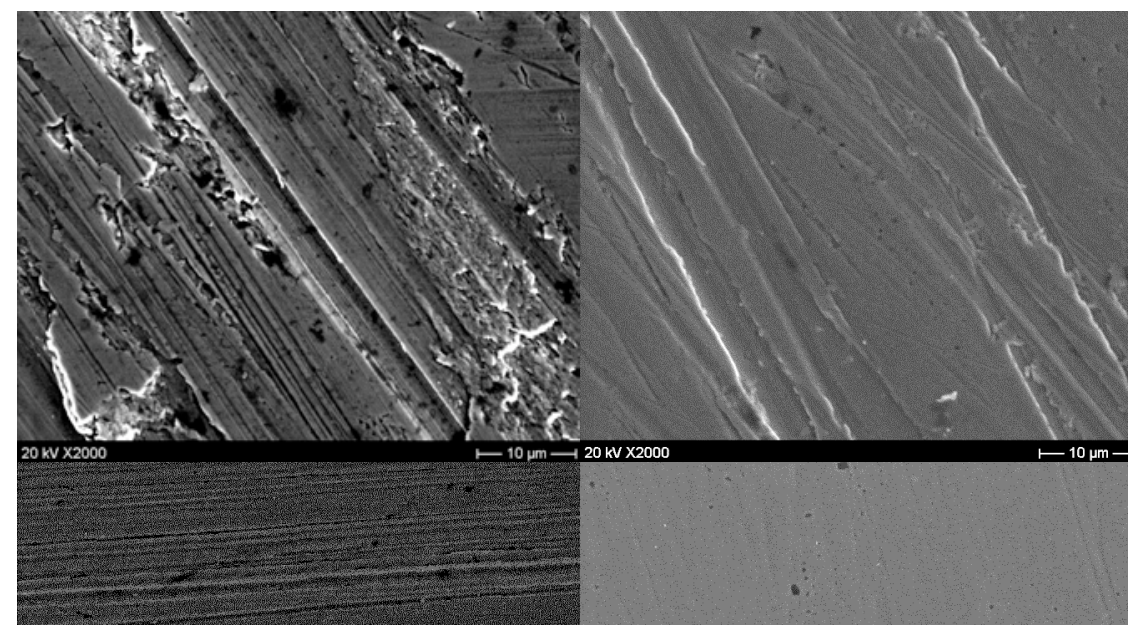

$\mathrm{C}$

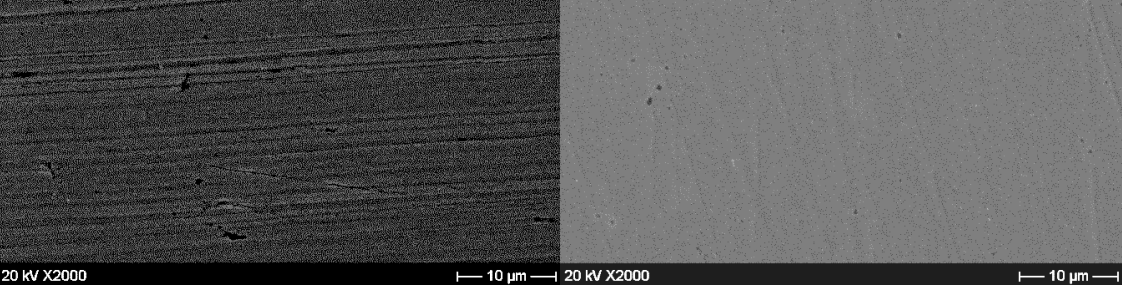

B

$\mathrm{D}$

Figure 23- 2000X SEM of surfaces attained by a) 60 grit, b) 320 grit, c) 800 grit, and d) mirror polishing.

A measure of the surface roughness of these samples was determined using both an optical and a contact profilometer, which are both capable of very accurate measurements of surface roughness parameters. $\mathrm{R}_{\mathrm{a}}$ and $\mathrm{R}_{\mathrm{q}}$ (real mean squared) are the parameters typically used to measure surface roughness and are calculated from a surface profile $r(x)$ from the following:

$$
R_{a}=\frac{1}{L} \int_{0}^{L}|r(x)| \mathrm{d} x \quad R_{Q}=\sqrt{\frac{1}{L} \int_{0}^{L} r^{2}(x) \mathrm{d} x}
$$

The real mean squared parameter is more useful in accounting for large deviations from the datum $(r=0)$. For comparison, the results of the pre-exposure surface roughness measurements for both $R_{a}$ and $R_{q}$ are shown in Figure 24: 


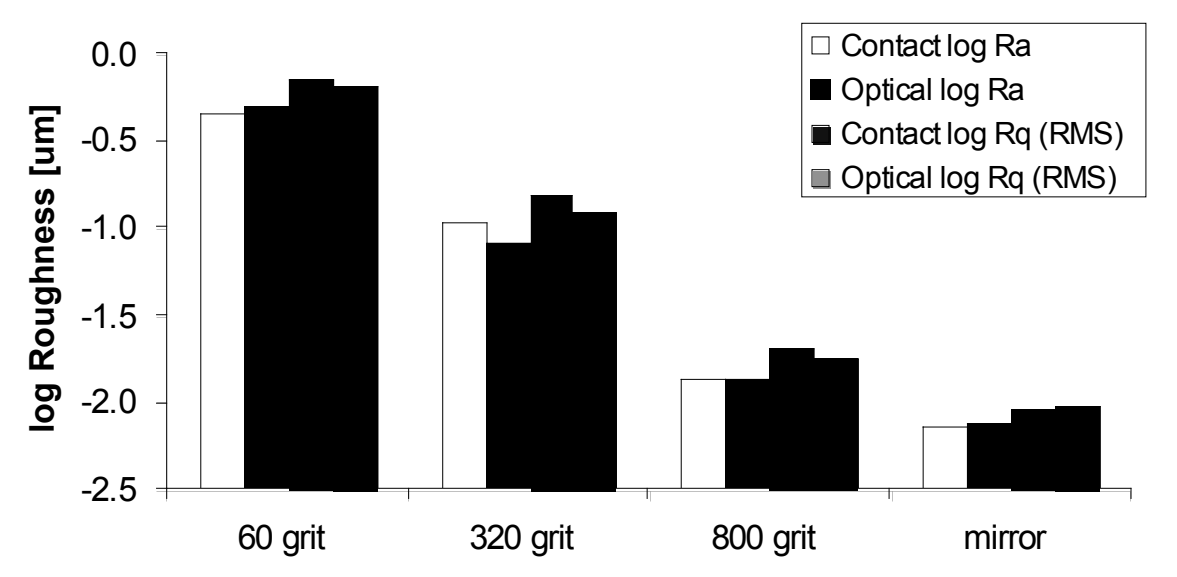

Figure 24-Surface roughness parameter measurements for surface roughness study.

The surfaces demonstrated a nice logarithmic trend, covering a wide enough range of surface roughness to adequately characterize the full scope of surface roughness effects. This trend is very similar for all instruments and parameters, and the optical $R_{q}$ measurements are chosen as the reference. (While the shot-peened samples also followed this trend with $\mathrm{R}_{\mathrm{q}} \sim 3$, it must be considered separately due to the additional compressive stresses induced and microstructural changes produced.)

The shot peened samples were prepared by blasting 800 grit polished samples with cut steel wire shot for 10 seconds evenly over both surfaces at a pressure of $40 \mathrm{psi}$ and a distance of $\sim 6$ inches. The microstructural change due to the process can be observed via an electron backscatter diffraction micrograph (See Figure 25).

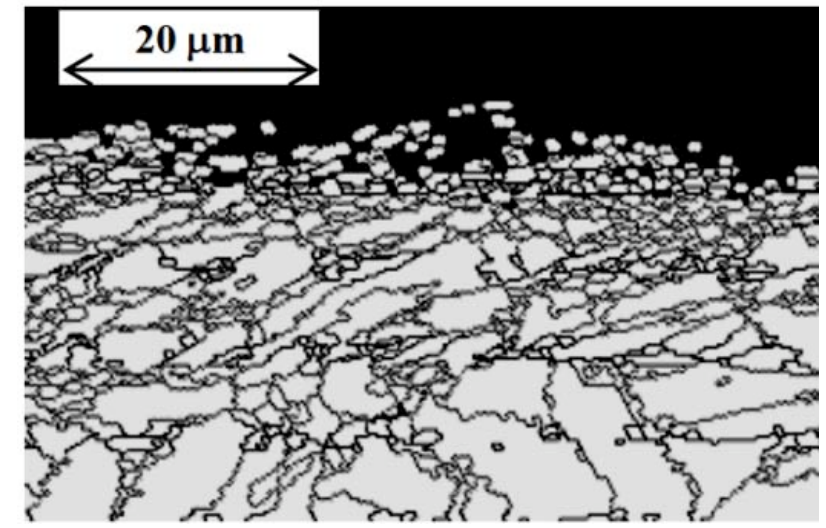

Figure 25- EBSD microstructure of NF616 shot peened for 5 seconds at 40 psi $^{\text {xvii }}$

This figure shows how near the surface the grain size is dramatically reduced and is followed by another region where grains are significantly flattened before returning to their normal random orientation at the bottom of the figure. The affected region for the parameters used for this test is approximately 10 microns deep.

\section{III.3.3 Experimental Conditions}

The sample exposures to lead-bismuth eutectic (LBE) were again carried out in the DELTA Loop at the Los Alamos National Laboratory. The nominal operating temperature of the loop was $535^{\circ} \mathrm{C}$ for the surface roughness and shot peening exposure. The LBE was flowing past the samples at a velocity of $1.2 \mathrm{~m} / \mathrm{s}$ and oxygen sensors were used to maintain an oxygen 
concentration near $1 \times 10^{-6} \mathrm{wt} \%$. Samples were exposed for three exposure durations (up to 630 hours) to study oxide formation and growth over time.

Post-test sample preparation involved careful cleaning, cutting, and mounting the samples for analysis, to preserve the corrosion product. For detailed identification of structural morphology of the oxide layers and measurement of oxide thickness, the samples were examined with a scanning electron microscope (SEM) in cross-section view. The Energy Dispersive Spectroscopy (EDS) capability of the SEM was used to identify chemical composition of the oxide layers.

\section{III.3.4 Surface Roughness}

The samples which were given different surface roughness preparations were examined with the SEM using backscatter electron imaging (BEI) to show maximum contrast by using the atomic mass differences between the LBE (shows up as bright white) the oxide (dark gray/black) and the bulk metal (gray). Many insights can be gathered by comparing representative images of all four conditions and all three times (See Figure 26).

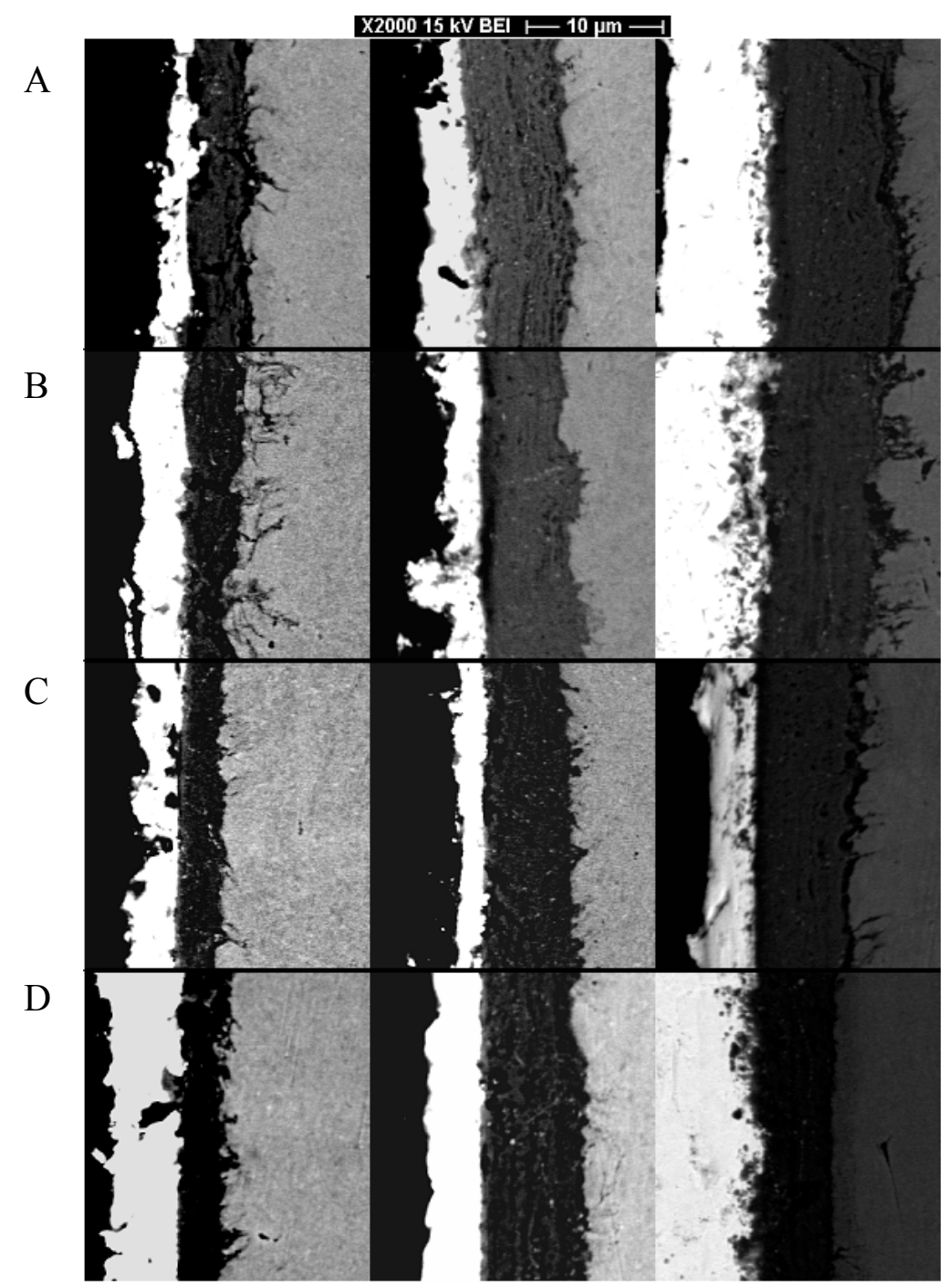

Figure 26- SEM images of 230, 430, and 630 hour (from left) exposed NF616 samples receiving surface preparations of a) 60 grit, b) 320 grit, c) 800 grit, and d) mirror polish. 
It can be seen for one that as expected the oxide layer is thinnest initially and continues to grow to 630 hours with the exception of the mirror polished sample which may indicate that some removal of the oxide layer is taking place. A significant result is that the diffusion zone seen in the mirror polished sample and previous experiments (such as the elemental surface treatment control samples which were also mirror polished) is not present in cases where intergranular corrosion is prevalent. The average oxide thicknesses were measured (not including diffusion zones or intergranular corrosion spindles) for each condition and time and are shown in Table IV.

\begin{tabular}{|c|c|c|c|c|}
\hline & mirror & 800 grit & 320 grit & 60 grit \\
\hline 230 hours & 3.31 & 3.25 & 3.78 & 3.92 \\
\hline 430hours & 7.15 & 6.01 & 6.00 & 6.66 \\
\hline 630 hours & 5.96 & 6.75 & 8.03 & 9.09 \\
\hline
\end{tabular}

These values are plotted against the real mean squared roughness parameter in Figure 27 and show a fairly linear (in fact logarithmic with $\mathrm{R}_{\mathrm{q}}$ ) trend after 630 hours.

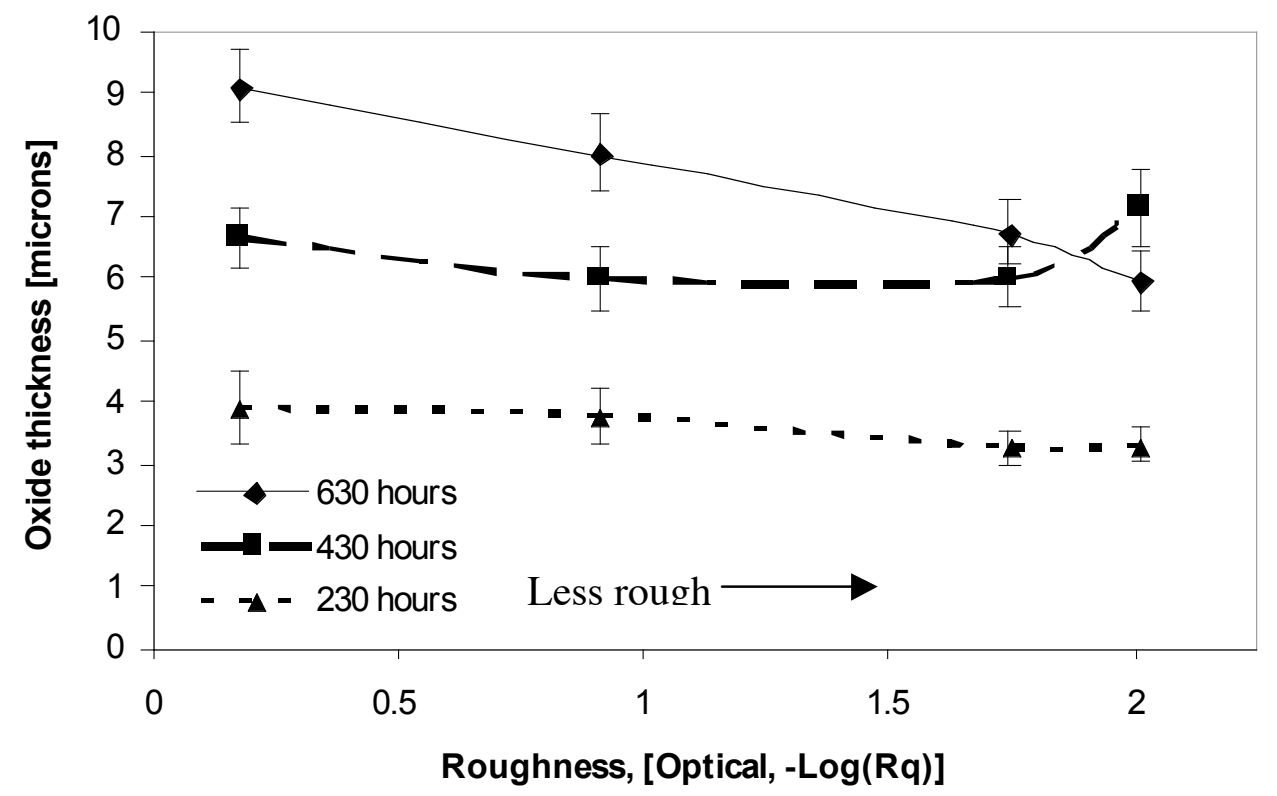

Figure 27 - Surface roughness versus oxide thickness.

One can see that in terms of oxide thickness only, the rougher the surface the thicker the oxide that will be formed after 630 hours. To investigate further the composition of oxide layers for various times and roughness, EDS linescans were taken for $\mathrm{Fe}, \mathrm{Cr}$, and $\mathrm{O}(\mathrm{Pb}$ and Bi were also counted but are left off of the plots for clarity). The 60 grit 230 hour sample had some of the outer magnetite remaining on the surface followed by the $\mathrm{Fe}-\mathrm{Cr}$ spinel and a sharp drop of to nominal bulk composition (See Figure 28). 


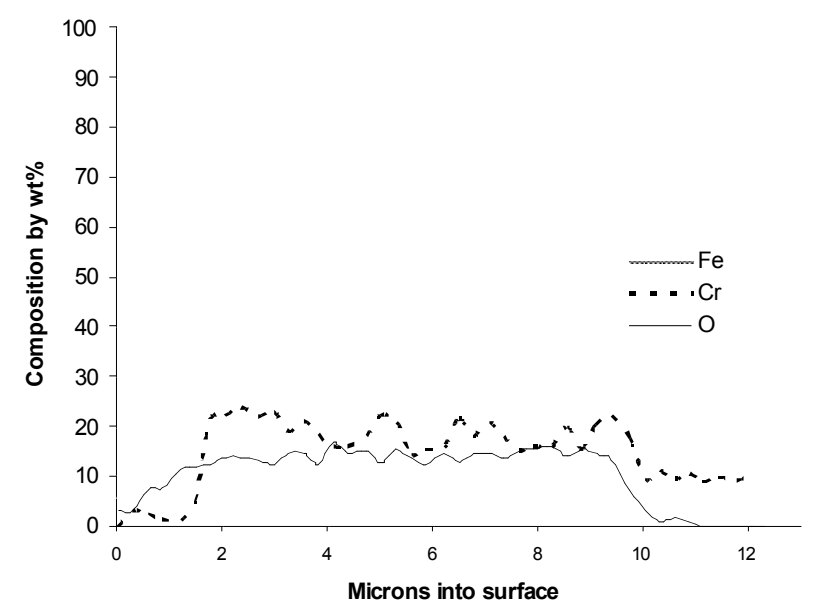

Figure 28- EDS composition linescan of 60 grit, 630 hour exposed NF616.

This contrasts to the 320 grit samples that do not show any remaining magnetite after 630 hours but do show an increase in $\mathrm{Cr}$ at the oxide/bulk interface (See Figure 29).

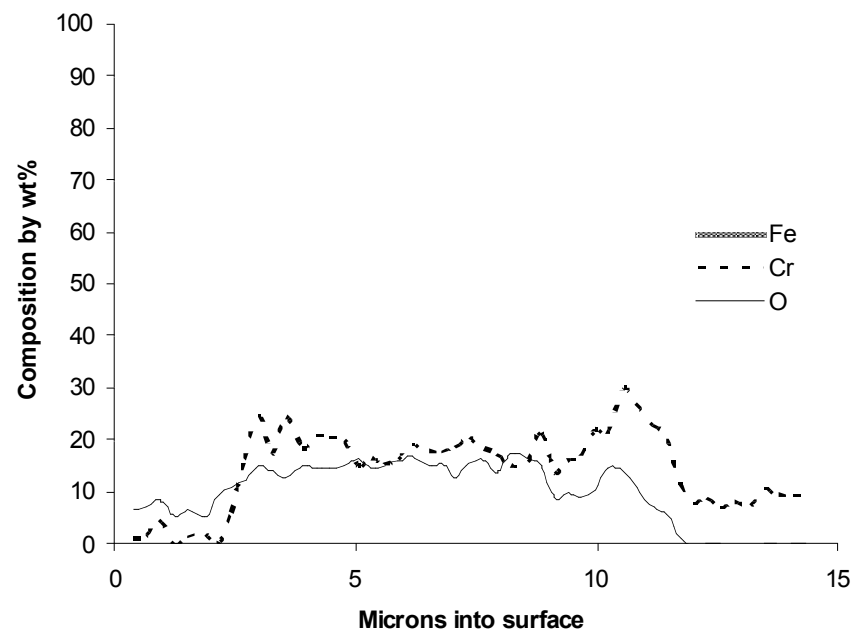

Figure 29- EDS composition linescan of 320 grit, 630 hour exposed NF616.

The removal of magnetite is also reflected by the much straighter interface between the LBE and the surface of the oxide in the 630 hour 800 grit sample than the 60 grit sample (See Figure 26). Additionally, there is an enrichment of $\mathrm{Cr}$ at this sharp interface (See Figure 30). 


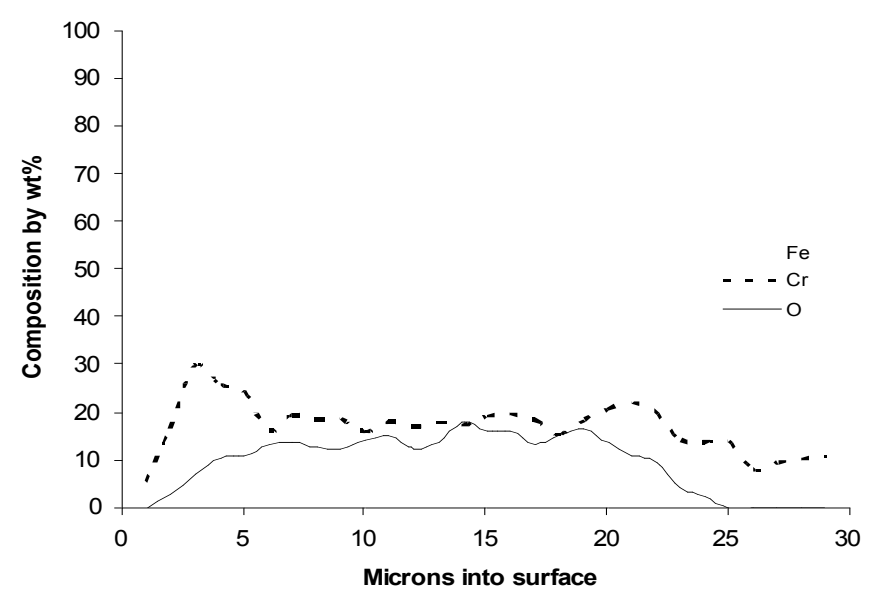

Figure 30 - EDS composition linescan of 800 grit, 630 hour exposed NF616.

The mirror finished sample EDS linescan (Figure 31) shows an increase in Cr right before a more gradual drop off of $\mathrm{Cr}$ and $\mathrm{O}$ indicative of the diffusion zone that can be seen in the SEM image.

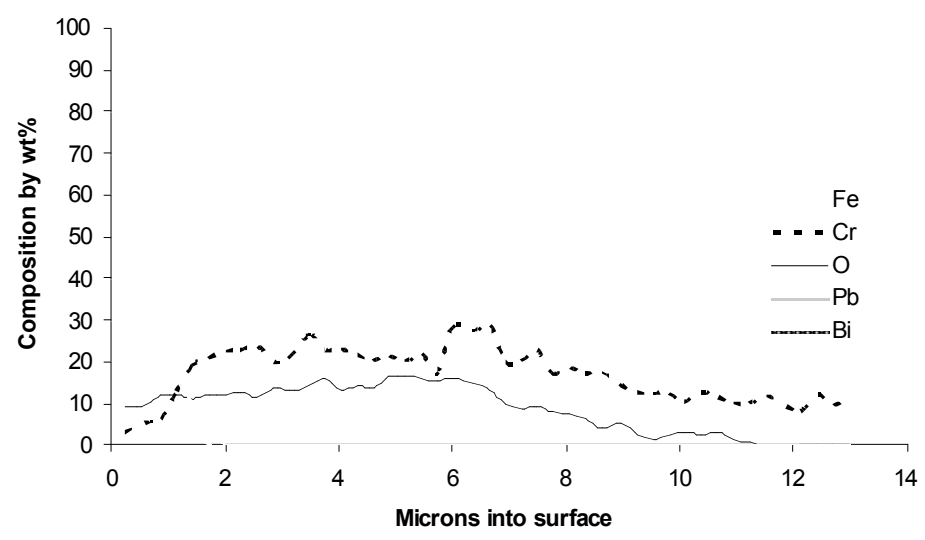

Figure 31- EDS composition linescan of mirror polished, 630 hour exposed NF616.

To summarize the findings of the SEM and EDS linescan analysis, in general the oxide is comprised of an $\mathrm{Fe}-\mathrm{Cr}$ spinel with some enrichment of $\mathrm{Cr}$ at both the LBE/oxide and the oxide/bulk interfaces. The measured oxide thickness varied logarithmically with the surface roughness, but this does not appear to tell the whole story due to differing corrosion mechanisms; In the samples with rougher surfaces, intergranular corrosion was more prevalent, suggesting that oxygen did not diffuse into the bulk because instead it formed oxides along grain boundaries where the $\mathrm{Cr}$ was enriched (as seen in an EDS linescan across the boundary, not shown). Mirror polishing hence does have a significant effect on the corrosion mechanisms of steel in liquid lead-alloys. In the long term, one would expect the intergranular corrosion to pose more of a threat in terms of loss of material because it leads to intergranular failure. Additionally, the smooth surface of the oxides formed by the 800 grit and mirror polished samples should help reduce the shear stresses and mass transfer of metal species through the oxide to the liquid metal flow past the oxide compared to a rough interface which would promote local turbulence. On the other hand, a very smooth oxide/bulk interface could also lend itself to spallation of the film due to inadequate surface 
$\operatorname{contact}^{17}$, and hence the mirror polished surface may not necessarily provide the best long term corrosion protection.

\section{III.3.5 Shot Peening}

The shot peening samples were included in the same Delta Loop exposure as the surface roughness samples which can serve as the controls for this experiment. As mentioned previously, the shot peening process creates a surface rougher than even the 60 grit sample. One might expect the samples to follow a similar trend, however the effect of the changes in the surface grain structure must be significant because the SEM images for the shot peened sample (See Figure 32) show that the oxide growth was fairly uniform showing the spinel layer and diffusion zone similar to the mirror polished samples after 430 hours. However, after 600 hours the diffusion zone is supplanted by a region of severe intergranular corrosion.
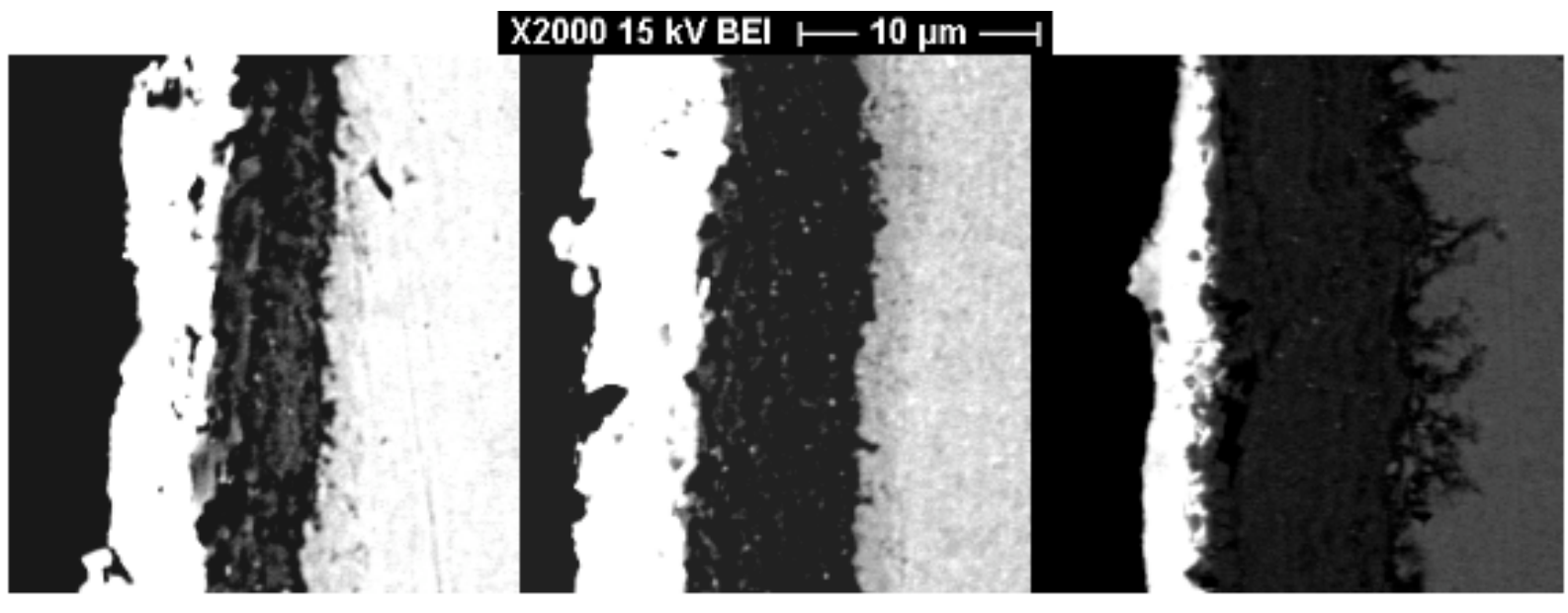

Figure 32-SEM images of 200, 400, and 600 hour (from left) exposed shot peened NF616.

It is possible that this is due to the fact that up to about 10 microns (i.e. the affected region of shot peening) the treatment served to promote a uniform protective oxide layer and inhibit intergranular corrosion, but once the layer grew past this region intergranular corrosion is again present due to the larger grain size in the bulk material. Hence, if the shot peening treatment were made to have a larger affected region than the expected long term oxide thickness by increasing the pressure or the time of application than a corrosion performance enhancement may be seen. For example, a shot peening treatment at 60 psi for 20 seconds on NF616 yields a large nanocrystalline region and a total affected depth of more than 20 microns as can be seen in the EBSD micrograph below (Figure 33). Additionally, these results indicate smaller grains, in general, may be more protective. 


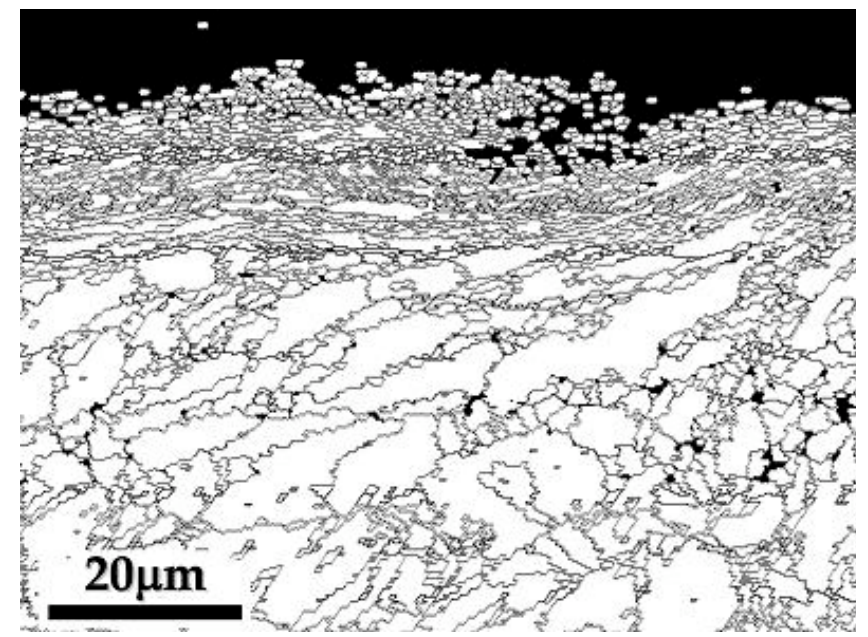

Figure 33- EBSD microstructure of NF616 shot peened for 20 seconds at $60 \mathrm{psi}^{12}$

\section{Oxidation and Corrosion Theory}

\section{IV.1 Protective oxide scale formation}

The in-situ formation of a protective oxide scale on the surface of the steel provides the ultimate corrosion barrier for materials to be used in high temperature, oxidizing environments. To ensure that the scale formed is indeed protective in nature, there are several key requirements for the system ${ }^{\text {xviii: }}$

1) Thermodynamic stability - The protective oxide must be thermodynamically more stable than oxides of lead or bismuth at the temperatures and oxygen concentration of the system.

2) Low diffusion - Limited movement of species through the oxide phases favors growth at the interface of various phases/regions which is inversely proportional to scale thickness. This leads to dense, compact oxides with parabolic growth characteristics.

3) Low scale-removal rate - If removal of the oxide scale by one of a number of mechanisms including volatilization, dissociation, mass transfer corrosion, or erosion is fast compared to oxide growth then there will be little or no protection from the oxide film.

4) Mechanical integrity - To remain adherent for long periods of time, the equilibrium thickness of the oxide must be less than the critical thickness at which the mechanical integrity is compromised.

There are several other requirements that may be important but will not be specifically addressed in this research. The scale must have adequate resistance to contaminants and impurities in and around the oxide scale as well as be impermeable to aggressive components such as nitrogen, sulfur, and carbon which may contribute to internal corrosion. For a nuclear system, the scale must also retain the aforementioned properties under irradiation. Lastly, there are several approaches to surface treatment (surface alloying, coatings, pre-oxidation, etc.) that can assist in the formation of more protective oxide. 


\section{IV.2 Physical model for complex oxide formation}

The classical treatment of complex oxidation of binary alloys (i.e. Fe-Cr) first developed by Wagner ${ }^{\mathrm{xix}}$ will be used to describe the oxidation behavior of the ferritic-martensitic steels under consideration for application in an LFR system. The duplex oxide that is typically formed in steels at high temperatures is due to the difference in thermodynamic stability and diffusion rates of iron and chromium. In an $\mathrm{Fe}-\mathrm{Cr}-\mathrm{Pb}-\mathrm{Bi}-\mathrm{O}$ system, the $\mathrm{Cr}$-oxides have more negative free energies and one would expect them to form the first layers in a complex oxide structure. However, since the concentration of $\mathrm{Cr}$ at the surface is low, it is expected that formation of a pure chromia $\left(\mathrm{Cr}_{2} \mathrm{O}_{3}\right)$ layer is unlikely. Thermodynamic stability then predicts the $(\mathrm{Fe}, \mathrm{Cr})_{3} \mathrm{O}_{4}$ spinel and the $\mathrm{Fe}_{3} \mathrm{O}_{4}$ magnetite as the most likely oxide layers to be formed on the surface of steels at temperatures below $\sim 570^{\circ} \mathrm{C}$. At temperatures above $570^{\circ} \mathrm{C} \mathrm{FeO}$ (wustite) forms preferentially ${ }^{x x}$. The diffusion region which rests between the inner spinel and the bulk steel is likely the result of an increase in cation vacancies due to the outwards diffusion of iron through the oxide layers and is accompanied by additional inwards oxygen diffusion that does not yet result in complete oxidation. It appears that the removal rate of $\mathrm{Fe}_{3} \mathrm{O}_{4}$ is significantly greater than that of the spinel, resulting in full removal after a relatively short period of time at $530^{\circ} \mathrm{C}$. A schematic of the physical mechanisms that must be incorporated into a corrosion model is shown in Figure 34:

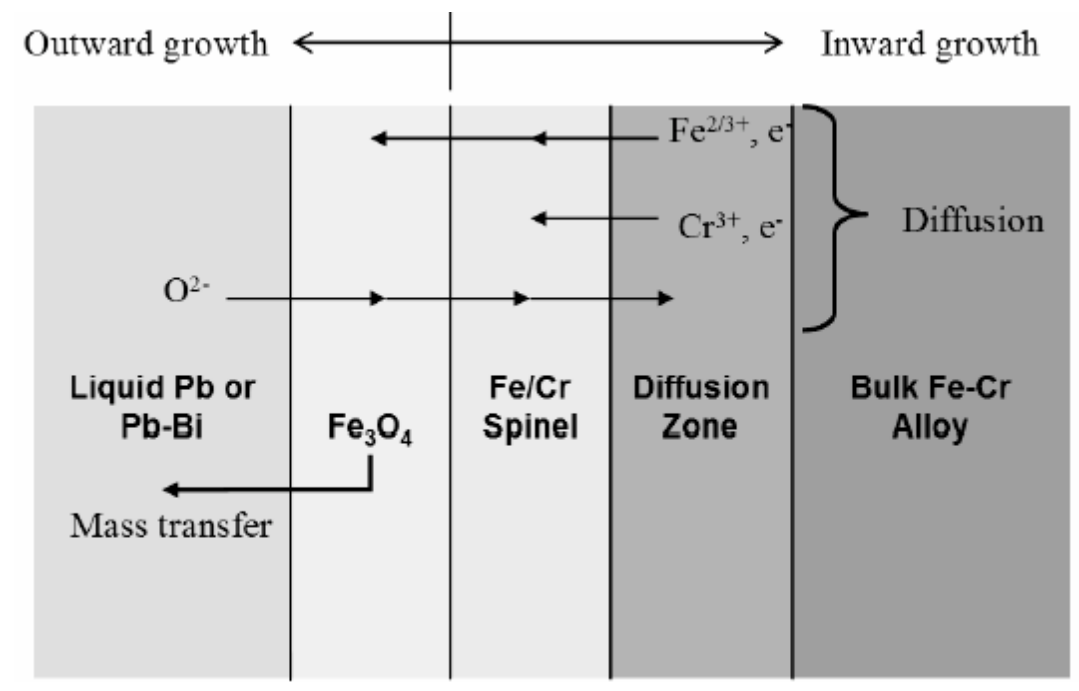

Figure 34 - Schematic illustration of corrosion mechanisms

The schematic illustrates the diffusion of various species through the complex oxide layers formed and provides a basis for constructing the corrosion model. The inner oxide layer, enriched in $\mathrm{Cr}$, serves as the ultimate protective oxide layer. Oxidation is driven by diffusion of iron (and chromium to a lesser extent) cations out of the diffusion zone in the bulk through the oxide layers and simultaneous inwards diffusion of oxygen through the oxide layers to the diffusion zone. The magnetite/spinel interface lies at the original liquid/metal interface.

Based on this physical model and the known diffusion behavior of various species, a prediction can be made about the $\mathrm{Fe}, \mathrm{Cr}$, and $\mathrm{O}$ concentrations in the various layers. One would expect the oxygen content to be the greatest in the oxide layers and drop off through the diffusion zone to zero in the bulk ${ }^{\mathrm{xxi}}$. Chromium should be nearly nonexistent in the outer layer, greatest in the spinel layer, and back to the alloy concentration in the bulk. Lastly, iron should be prevalent in the outer layer but be suppressed in the spinel and diffusion zone before rising back to its alloy concentration in the bulk. An EDS linescan along the cross 
section of an $\mathrm{HCM} 12 \mathrm{~A}$ sample exposed at a lower temperature $\left(460^{\circ} \mathrm{C}\right.$, at which magnetite removal is not observed) demonstrates these trends (See Figure 35):

Composition Through Layers

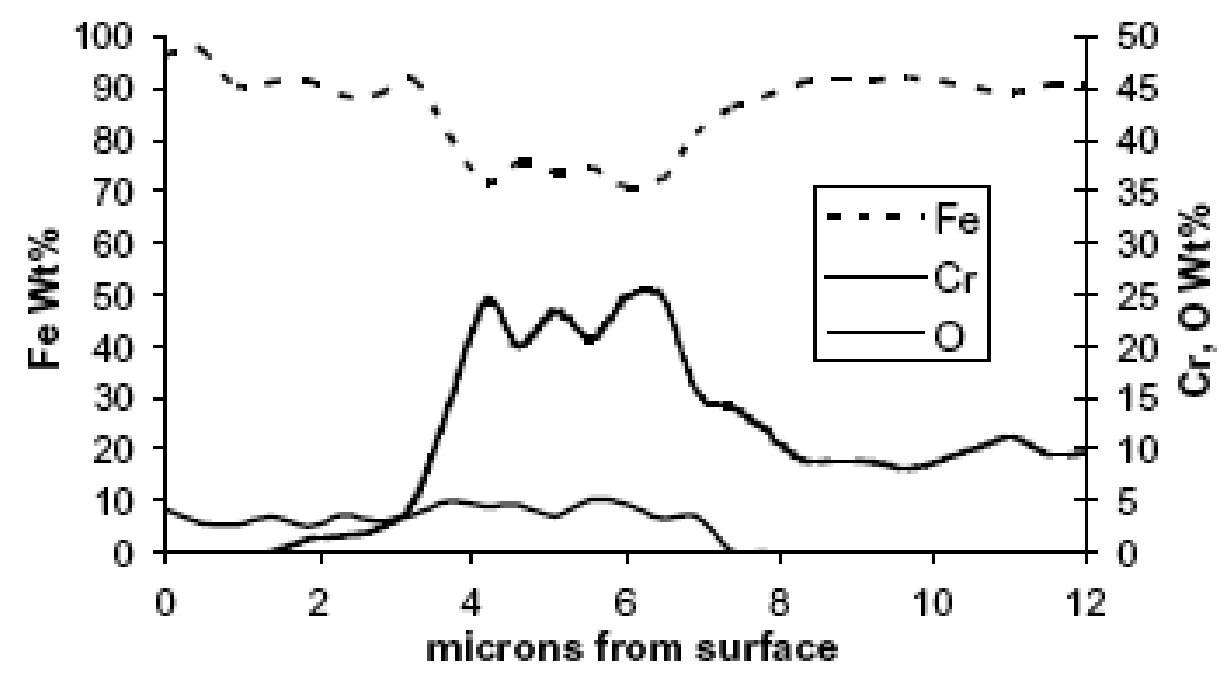

Figure 35 - Fe, $\mathrm{Cr}$, and $\mathrm{O}$ content through oxide layers of $\mathrm{HCM} 12 \mathrm{~A}$ exposed to $\mathrm{LBE}$ at $460^{\circ} \mathrm{C}$.

\section{IV.3 Tedmon's equation and rate constants}

The duplex oxide structure found in our experimental results is predicted by thermodynamics and Wagner's diffusion theory and is not unique to the lead-alloy environment. However, the removal of the outer oxide (in this case by the flowing LBE) is not as commonly seen is lighter mass coolants like water. When oxide layers experience simultaneous growth and removal, a more appropriate treatment for the oxide growth rate, based on Tedmon's equation $^{\text {xii }}$ (Eq. 1) which was first used to describe scale volatilization of Cr-oxide, can be examined:

$$
\frac{d \delta}{d t}=\frac{K_{p}}{2 \delta}-K_{r}
$$

where $\delta$ is the oxide thickness, $\mathrm{t}$ is time, $\mathrm{K}_{\mathrm{p}}$ is the parabolic oxide growth rate constant and $\mathrm{K}_{\mathrm{r}}$ is the linear scale removal rate constant. Solving for oxide thickness in time yields asymptotic behavior where the thickness will approach some limiting thickness $\delta_{\mathrm{c}}$ regardless of initial thicknesses (Eq. 2, ${ }^{\mathrm{xvi}}$ ):

$$
\delta(t \rightarrow \infty)=\delta_{\mathrm{c}}=\frac{K_{p}}{2 K_{r}}[\mu \mathrm{m}]
$$

This solution assumes that the limiting thickness is less than the critical thickness for mechanical breakdown. Zhang and $\mathrm{Li}^{\mathrm{xvi}}$ extend the solution to weight change over time, where a maximum weight gain will be realized during an initial growth dominated period followed by what eventually becomes a linear material loss rate in the latter removaldominated period. An expression for the long-term material thinning rate based on the scale 
removal rate $\left(\mathrm{K}_{\mathrm{r}}\right)$, densities of the oxide and steel $\left(\rho_{\mathrm{M}_{\mathrm{x}} \mathrm{O}}, \rho_{\mathrm{M}}\right)$ and mass fraction of oxygen in the oxide $\left(\mathrm{F}_{\mathrm{O}}\right)$ follows (Eq. $\left.3,{ }^{\mathrm{xvi}}\right)$ :

$$
\mathrm{R}_{\mathrm{r}}=\frac{\rho_{\mathrm{M}_{\mathrm{x}} \mathrm{O}_{y}}}{\rho_{\mathrm{M}}}\left(1-\mathrm{F}_{\mathrm{O}}\right) \mathrm{K}_{\mathrm{r}} \quad[\mu \mathrm{m} / \mathrm{yr}]
$$

This calculated loss rate $\left(\mathrm{R}_{\mathrm{r}}\right)$ is an important parameter in determining material lifetime in a lead-alloy cooled reactor environment and provides a useful metric with which to compare materials. In summary, the analysis based on Tedmon's equation provides a means for assessing the long-term performance of materials if the growth and removal rate constants are known. To determine the rate constants, an effort is made to apply theory and experimental data to build a comprehensive model for the overall corrosion behavior.

\section{IV.3.2 Determining Growth Rate Constant}

Wagner's treatment is valid for diffusion-limited, high-temperature, compact scale formation. In Wagner's treatment, oxidation proceeds by cation ( $\mathrm{Fe}$ and $\mathrm{Cr}$ ) diffusion from the bulk metal to the surface and oxygen anion diffusion from the environment into the bulk metal, and the reactions at phase boundaries are assumed to be relatively rapid ${ }^{\text {xiii }}$. The result is a parabolic oxide growth rate constant $\mathrm{K}_{\mathrm{p}}$ that is dependant on diffusion coefficients of metal cations $\left(\mathrm{D}_{\mathrm{m}}\right)$ and oxygen anions $\left(\mathrm{D}_{\mathrm{O}}\right)$ and partial pressures of oxygen at the scale interfaces (Eq. 4, [2]):

$$
\mathrm{K}_{p}=\int_{\left(\mathrm{P}_{\mathrm{O}_{2}}\right) I I}^{\left(\mathrm{P}_{\mathrm{O}_{2}}\right) I}\left(\alpha D_{m}+D_{O}\right) d \ln P_{O_{2}}
$$

where $\alpha$ is the oxygen/metal atom ratio (i.e. 4/3 for magnetite) and I and II represent the oxide/bulk and oxide/LBE interfaces, respectively. The oxygen partial pressures at the interfaces can be set to the dissociation oxygen partial pressure of the oxides that are formed $^{\mathrm{xxiv}}$, but the diffusion coefficients must be determined.

\section{IV.3.3 Diffusion}

The relative difference in diffusion rates of iron and chromium are important in driving the formation of the complex oxide. Because the diffusion of chromium through bulk alloys and oxides is much slower than that of iron $^{\text {xxi }}, \mathrm{Cr}$ can be treated as relatively immobile compared to Fe. Thus, while Fe cations are free to move through the inner spinel layer and form the pure iron oxide at the original bulk/LBE interface, oxidation of iron and chromium also progresses inward via diffusion of oxygen from the molten LBE environment through the oxide layers. Recalling the second protective oxide requirement, diffusion of oxide molecules is considered negligible such that the movement of Fe cations and oxygen anions are the rate limiting events. Hence, the next logical step in the development of the corrosion model is to determine diffusion coefficients for $\mathrm{Fe} / \mathrm{Cr}$ and $\mathrm{O}$ through the bulk alloy and oxide layers. These oxidation mechanisms will be revisited after comparison to experimental results. 
The radiotracer-derived Ahrrenius correlation from Castle, et al. for oxygen in magnetite under similar oxygen partial pressures and temperatures that was used for the calculations in this study is shown here (Eq. $\left.5,{ }^{x x v}\right)$ :

$$
D_{O}=3.2 \times 10^{-10} \exp \left(-\frac{17000}{R T}\right)\left[\mathrm{m}^{2} / \mathrm{s}\right](5)
$$

Use of this correlation assumes a dense, compact oxide scale, whereas the actual oxygen diffusion rates can be accelerated due to porosity or cracks in the oxide layer. As will be seen below, using the above diffusion coefficient still allowed for reasonable correlation between model and measurements.

Cation diffusion requires further consideration owing to the several mechanisms by which diffusion can take place in the oxide, all of which are highly dependant on the nature of the oxide itself. The cation diffusion coefficient in the oxide was determined by using a combination of correlations that account for both lattice diffusion and grain boundary diffusion while adjusting for grain size and oxide density. Diffusion can occur via migration of point defects in the lattice structure or via fast diffusion pathways such as grain boundaries and dislocations. The concentration of point defects depends largely on non-stoichiometry and impurities in the oxide structure while fast pathways are dependant on grain size and mechanical stresses. The correlation developed by Dieckmann and Schmalzried (Eq. 6, ${ }^{\text {xxiv }}$ ) used to account for vacancy $\left(\mathrm{D}_{\mathrm{V}}{ }^{\circ}\right)$ and interstitial $\left(\mathrm{D}_{I}^{\circ}\right)$ point-defect diffusion in magnetite is:

$$
D_{m}=\left(D_{V}^{o} \exp \left(-\frac{138600}{R T}\right)+D_{I}^{o} \exp \left(-\frac{614200}{R T}\right)\right) P_{O_{2}}{ }^{-2 / 3} \quad \mathrm{~m}^{2} / \mathrm{s}
$$

where values for vacancy $\left(\mathrm{D}_{\mathrm{v}}{ }^{\circ}\right)$ and interstitial $\left(\mathrm{D}_{I}^{o}\right)$ diffusion coefficients were found experimentally to be $4 \times 10^{-15} \mathrm{~m}^{2} / \mathrm{s}$ and $8 \times 10^{3} \mathrm{~m}^{2} / \mathrm{s}$, respectively. Diffusion via point defects through the bulk spinel grains is not expected to vary much from magnetite due to similarity in bulk grain lattice structure. Since the point defect model is expected to underestimate the diffusion coefficients because the fast pathway diffusion is not appropriately represented, a simple correction can be made based on grain size of the oxide scale measured via EBSD technique (Eq. $\left.7,{ }^{\mathrm{xv}}\right)$. The Oxide Handbook ${ }^{x x v i}$ reports a correlation for grain boundary $\left(D_{g b}\right)$ diffusion (Eq. 7, $\left.{ }^{\mathrm{xxv}}\right)$ :

$$
D_{g b}=1.27 \times 10^{-3} \exp \left(-\frac{151562}{R T}\right)\left[\mathrm{m}^{2} / \mathrm{s}\right]
$$

such that an effective diffusion rate $D_{m, \text { eff }}$ may be calculated for cations through the scale using the following (Eq. 8, ${ }^{\text {xiv }}$ ):

$$
D_{m, \text { eff }}=D_{m}(1-\Phi)+D_{g b} \Phi, \quad \Phi=\frac{2 \varepsilon}{\mathrm{g}}
$$

where $\Phi$ signifies the fraction of fast pathway diffusion sites and can be approximated by treating grains as rectangular prisms with height and width $\mathrm{g}$ and length $\varepsilon$ (comes to about 96 using measurements from a study by Tan, et al. ${ }^{\mathrm{xv}}$ for $\mathrm{HCM} 12 \mathrm{~A}$ at $530^{\circ} \mathrm{C}$ ). The final estimate for cation diffusion in the oxide was thus determined by using Eqs. 7-8 to adjust the result from the point defect model (Eq. 6). 


\section{IV.4 Mass transfer corrosion}

Zhang and Li proposed a model for the mass transfer corrosion at the solid-liquid interface which relates the difference in concentrations of species at the interface and in the bulk to a mass transfer coefficient $k_{m}$ (Eq. 9, ${ }^{\text {xxvii }}$ ):

$$
R_{m}=k_{m}\left(c_{s}-c_{b}\right) \quad[\mu \mathrm{m} / \mathrm{yr}]
$$

The concentration of iron at the oxide surface $\left(\mathrm{c}_{\mathrm{s}}\right)$ is calculated based on a correlation from Sannier and Santarini in pure lead (Eq. 10, ${ }^{\text {xviii }}$ ):

$$
\log \left(c_{s}\right)=\left(4.34-\frac{3450}{T[K]}\right) \quad[\mathrm{ppm}]
$$

and the bulk concentration $\left(\mathrm{c}_{\mathrm{b}}\right)$ is negligible for the short times in this study. The calculated mass transfer corrosion rate $\mathrm{R}_{\mathrm{m}}$ can then be calculated and compared to the measured removal rate $\mathrm{R}_{\mathrm{r}}$. The mass transfer corrosion rate constant $k_{m}$ can be calculated analytically by the following expression developed for mass transfer in fluid flow derived by Zhang and Li (Eq. $\left.11,{ }^{\text {xxvii }}\right)$ :

$$
k_{m}=\frac{3}{2 \Gamma\left(\frac{1}{3}\right)}\left(\frac{3}{1740}\right) v^{-2 / 3} D^{2 / 3} V\left(\frac{\lambda}{2}\right)^{1 / 2}
$$

where $v$ is the kinematic viscosity, $\mathrm{V}$ is the flow velocity, $\lambda$ is the Fanning friction factor, and $\mathrm{D}$ is the diffusion coefficient for iron in lead, for which the following correlation found by Robertson was used (Eq. 12, ${ }^{\text {xxiv }}$ ):

$$
D_{F e \rightarrow P b}=4.9 \times 10^{-7} \exp \left(-\frac{44100}{R T}\right)\left[\mathrm{m}^{2} / \mathrm{s}\right]
$$

Substituting for the Gamma function $(\Gamma(1 / 3)=2.6789)$ and using the well-known Blasius correlation for turbulent flow $\left(\lambda=.0791 \mathrm{Re}^{-.25}\right)$ in Eq. 11 yields the following simplification, where $d$ is the hydraulic diameter (Eq. 13, ${ }^{\text {xxvii }}$ ):

$$
k_{m}=.0133 v^{-.542} D^{.667} V^{.875} d^{-.125}
$$

To facilitate component lifetime predictions, a physically based model that describes longterm corrosion is required. This work employs a proposed model as an initial basis for corrosion prediction and compares the model to measurements of oxide growth of materials exposed to lead bismuth eutectic (LBE) at high temperatures. The proposed model is based on the assumption that there are two kinetic processes in competition: 1) oxidation by simultaneous inward diffusion of oxygen and outward metal ion diffusion and 2) oxide scale removal from the steel surface into the flowing lead-alloy environment ${ }^{\text {xxiv }}$. Since these two processes have opposite effects on the oxide thickness, there will be a limiting oxide 
thickness $\left(\delta_{c}\right)$ which can be determined based on the diffusion rates of the species through the surface layers and the removal rate at the surface. Such a model should ultimately be able to explain the oxidation behavior observed in this and previous studies, arriving at a comprehensive model to predict corrosion in a flowing lead-alloy environment.

\section{Modeling and Benchmarking Results}

\section{V.1 Theoretical Calculations}

\section{Parabolic Rate Constant}

The rate constant calculation follows using the previously discussed methods (Section 2) at $530^{\circ} \mathrm{C}$. The oxygen partial pressures were set to approximate values for oxide dissociation at the boundaries (using the Richardson-Jeffes diagram ${ }^{\text {xviii }} @ 530 \mathrm{C}: \sim 1 \times 10^{-27}$ for $\mathrm{Fe}_{3} \mathrm{O}_{4}$ oxide dissociation at the liquid/oxide interface and $\sim 5 \times 10^{-31}$ for the oxide/diffusion zone interface). The value of the partial pressure at the oxide/diffusion zone interface is set slightly higher than the dissociation partial pressure of $(\mathrm{Fe}, \mathrm{Cr})_{3} \mathrm{O}_{4}$ because the selective oxidation clearly extends into the metal and is expected to follow an exponential decay law through the internal oxidation layer ${ }^{\mathrm{xxi}}$. It should be noted that the diffusion coefficients are highly sensitive to these $\mathrm{P}_{\mathrm{O} 2}$ estimates. This said, the corrections made by adjustments for diffusion mechanisms and grain size above have relatively little effect in determining the order of magnitude for the diffusion coefficient, but are useful in estimating relative differences between differing oxide properties. The diffusion coefficients using Eqs. 5-8 are calculated to be $1.43 \times 10^{-13} \mathrm{~m}^{2} / \mathrm{s}$ for the cation diffusion coefficient and $2.51 \times 10^{-15} \mathrm{~m}^{2} / \mathrm{s}$ for the anion diffusion coefficient. The final calculated parabolic growth rate was about an order higher in magnitude than reported calculated values from previous studies by Zhang and Li, Saito, et al, and Smith, et al. at $550^{\circ} \mathrm{C}^{\mathrm{iv}}$, and all are presented in Table $\mathrm{V}$ for comparison:

Table V-Comparison of theoretical growth rate constants

\begin{tabular}{|r|c|}
\cline { 2 - 2 } \multicolumn{1}{c|}{} & $\mathbf{K p ~}\left[\mathrm{m}^{2} / \mathbf{s}\right]$ \\
\hline This study & $1.16 \mathrm{E}-16$ \\
\hline Zhang, Li & $3.21 \mathrm{E}-17$ \\
\hline Saito, et al. & $4.75 \mathrm{E}-18$ \\
\hline Smith, et al. & $2.64 \mathrm{E}-17$ \\
\hline
\end{tabular}

The reasons for this discrepancy likely lies in a difference in the diffusion coefficients used, since certain correlations used may underestimate overall diffusion rates. It will be seen later that the higher value for the growth rate constant agrees better with the experimental results of this work.

\section{Scale removal rate constant}

A number of assumptions about the system flow parameters must be made for the calculation of mass transfer corrosion rate. The input values for Eqs. 9 and 13 used for the removal rate calculation were: calculated iron diffusion coefficient in lead of $6.55 \times 10^{-10} \mathrm{~m}^{2} / \mathrm{s}$ (Eq. 12), experimental flow velocity of $1.2 \mathrm{~m} / \mathrm{s}$, experimental temperature of $530^{\circ} \mathrm{C}$, dynamic viscosity of $1.33 \times 10^{-7} \mathrm{~m}^{2} / \mathrm{s}^{\text {xxiv }}$, experimental hydraulic diameter of $.01 \mathrm{~m}$, and saturation concentration 
$\left(\mathrm{c}_{\mathrm{s}}\right)$ of $7.68 \times 10^{-8} \mathrm{~g} / \mathrm{m}^{3}$ with negligible bulk concentration $\left(\mathrm{c}_{\mathrm{b}}\right)^{\mathrm{xvi}}$. Using the calculated result for $R_{m}$ (Eq. 9) as the thinning rate $R_{r}$ in Eq. 3 to obtain a value for $\mathrm{K}_{\mathrm{r}}$ gives $2.03 \times 10^{-12} \mathrm{~m} / \mathrm{s}$, compared to a value of $9.10 \times 10^{-13} \mathrm{~m} / \mathrm{s}$ calculated by Zhang and $\mathrm{Li}$ at $550^{\circ} \mathrm{C}^{\mathrm{iv}}$. This corresponds to a long term thinning rate of about 37.6 microns per year (12.7 from Zhang and $\mathrm{Li}$ ). The reason for the higher estimate despite a slightly lower temperature is due to different assumptions for the hydraulic diameter and flow velocity parameters in the mass transfer corrosion model; this study examines an individual sample holder channel whereas Zhang and Li's calculations are for the larger piping of the Delta loop (hydraulic diameter $\sim 2.5 \mathrm{~cm})^{\mathrm{xxiv}}$.

\section{V.2 Comparison with Experimental Results}

The total (oxide layer plus diffusion zone) thickness data from the test is fit using a least squares method to the early stage kinetic approximation for the Tedmon model as in the treatment by Zhang, et al. ${ }^{\text {xi }}$ which give Eq. 14 for oxide thickness $\delta$ :

$$
\delta=\left(K_{p} t\right)^{(1 / 2)}-\frac{2}{3} K_{r} t
$$

where $K_{p}$ again is the growth rate constant, $t$ is time, and $K_{r}$ is the removal rate constant. The experimental results were fitted to Eq. 14 using a least squares technique to obtain values for $\mathrm{K}_{\mathrm{p}}$ and $\mathrm{K}_{\mathrm{r}}$ and are plotted in Figure 36 along with the measured total thickness (oxide plus diffusion zone) data from the $530^{\circ} \mathrm{C}$ test:

\section{Experimental Oxide Growth}

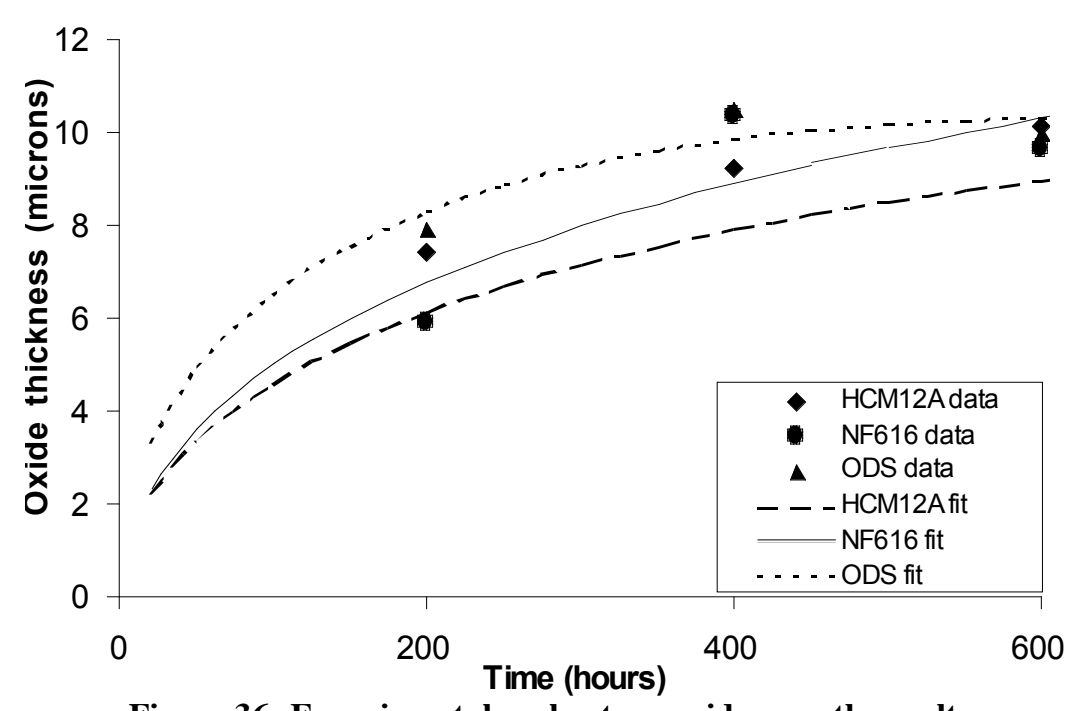

Figure 36- Experimental early-stage oxide growth results.

Equation 14 can also be used to plot the oxide thickness calculated using the growth and removal rate constants derived from Eqs. 3, 4, 9, \& 13 (Figure 37), showing excellent agreement with the experimental data: 


\section{Theoretical Oxide Growth}

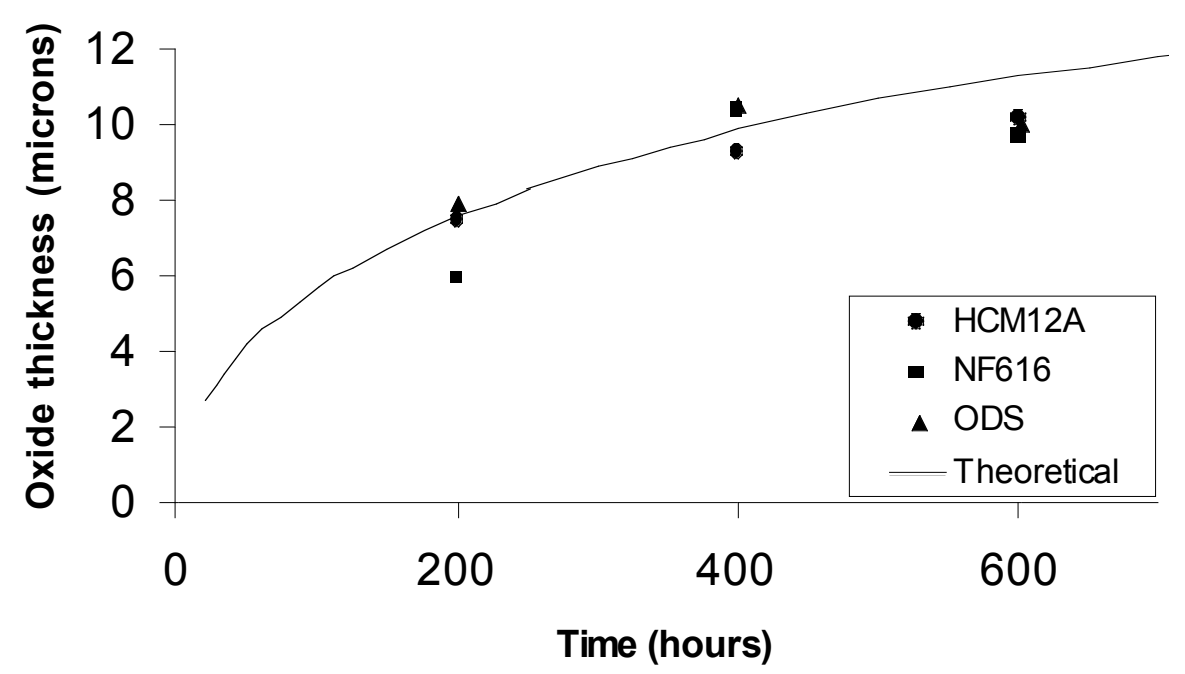

Figure 37- Theoretical values for oxide growth using early stage kinetics with total thickness data from the $530^{\circ} \mathrm{C}$ test

The experimentally obtained values for the growth rate constant $K_{p}$ and the removal rate constant $K_{r}$ from the least squares fitting are listed in Table VI along with the corresponding calculated values for removal rate $R_{r}$ (using Eq. 3) and limiting thickness $\delta_{c}$ (using Eq. 2). For comparison, fitting results from two alloys in a longer $\left(3000\right.$ hours, $\left.550^{\circ} \mathrm{C}\right) \mathrm{Zhang}$ and $\mathrm{Li}$ study $^{\text {iv }}$ are included.

Table VI - Tedmon's equation fitting results for experimental data

\begin{tabular}{r|c|c|c|c|}
\multicolumn{1}{c}{} & $\mathbf{K}_{\mathrm{p}}\left[\mathrm{m}^{2} / \mathbf{s}\right]$ & $\mathbf{K}_{\mathbf{r}}[\mathrm{m} / \mathbf{s}]$ & $\mathbf{R}_{\mathbf{r}}[\mu \mathrm{m} / \mathbf{y r}]$ & $\boldsymbol{\delta}_{\mathbf{c}}$ \\
\cline { 2 - 5 } HCM12A & $1.27(+/-0.2) \mathrm{E}-16$ & $4.45(+/-0.6) \mathrm{E}-12$ & $43.2(+/-5.7)$ & $14.3(+/-0.4)$ \\
\cline { 2 - 5 } NF616 & $8.63(+/-1.4) \mathrm{E}-17$ & $2.31(+/-0.6) \mathrm{E}-12$ & $22.4(+/-5.5)$ & $18.7(+/-1.0)$ \\
\cline { 2 - 5 } ODS & $1.84(+/-0.3) \mathrm{E}-16$ & $6.70(+/-0.6) \mathrm{E}-12$ & $65.1(+/-5.4)$ & $13.8(+/-0.6)$ \\
\cline { 2 - 5 } HT9, Zhang, Li & $1.48 \mathrm{E}-16$ & $1.01 \mathrm{E}-13$ & 14.0 & 73.6 \\
\cline { 2 - 5 } D9, Zhang, Li & $6.87 \mathrm{E}-17$ & $7.04 \mathrm{E}-13$ & 9.8 & 48.8 \\
\cline { 2 - 5 } & \multicolumn{2}{|c}{}
\end{tabular}

Both the parabolic growth rate constants and the mass transfer removal rate constants are on the order of those predicted by the model. The removal rate for HCM12A is within error of the $37.6 \mathrm{um} / \mathrm{yr}$ predicted by the theoretical calculation, whereas NF616 is slightly less and ODS is somewhat higher. The limiting thicknesses of around 15 microns agree well with those observed in the corrosion experiments, especially compared to those predicted by Zhang and Li which are much larger than has been seen experimentally. In summary, faster overall thinning rates and thinner limiting oxide thicknesses are predicted compared to the results of Zhang and $\mathrm{Li}$, just as with the theoretical calculations.

\section{Construction of a Molten Lead Corrosion Apparatus (MLCA)}

Although the DELTA Loop at Los Alamos is sufficient for studying the effects of LBE at standard power producing LFR operating temperatures $\left(\sim 500-600^{\circ} \mathrm{C}\right)$, there is a need for the ability to study the effects of pure lead for use as a coolant at temperatures exceeding $800^{\circ} \mathrm{C}$ (the temperatures necessary for efficient hydrogen production using advanced 
thermochemical processes). Therefore, we have designing and constructed a Molten Lead Corrosion Apparatus (MLCA) at the University of Wisconsin to perform corrosion tests on a wide variety of advanced materials at elevated temperatures.

\section{b. Design and Construction}

Certain aspects of this apparatus have been designed to mimic the conditions of the DELTA Loop so that results between the two experiments can be compared, that would facilitate our future long-term collaboration with LANL. Therefore the sample coupon size and shape will be identical to those used in LANL Tests $1 \& 2$. The MLCA consists of two stainless steel tanks, each of which contain an alumina crucible, ceramic fiber heaters, alumina fiber insulation, and other various components for control and measurement.

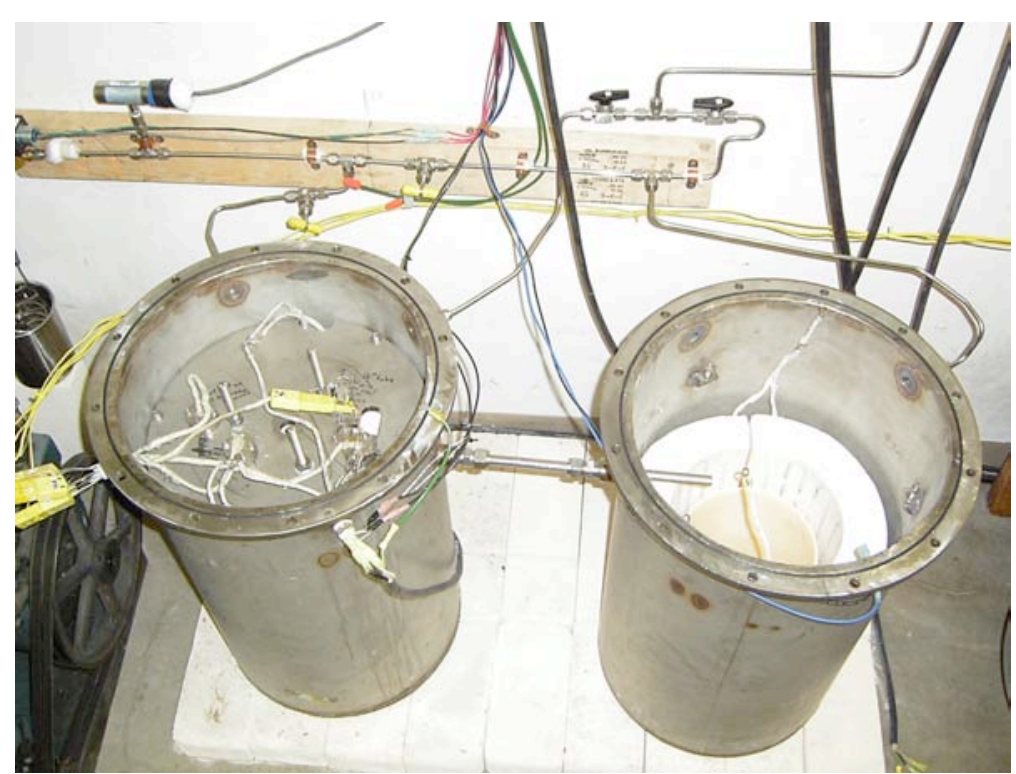

Fig. 38 - Inside of melt (left) and test (right) tanks showing thermocouple connections, ceramic fiber heaters, and the alumina crucible.

The test lead will be melted in one tank and transferred to the other by means of gas pressurization. In the "test tank", there will be an alumina sample holder that is capable of accommodating up to sixteen samples. Within this sample holder is an alumina propeller connected to a motor via an alumina shaft that will drive a flow of the molten lead past the samples. This is done in order to simulate the flow of liquid lead through a pipe as is the case in the DELTA Loop. 


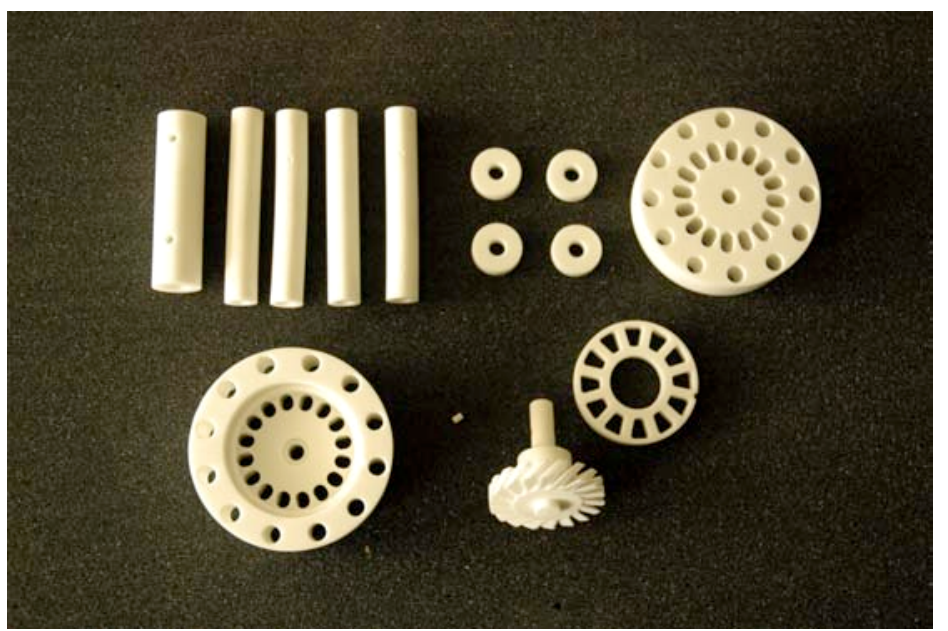

Fig. 39 - Components of the alumina sample holder and propeller.

Tests were performed with the propeller and sample holder in water and appropriate adjustments for lead were used order to determine the flow rate of lead that can be achieved. According to these calculations we can attain a flow rate of lead near the $1.2 \mathrm{~m} / \mathrm{s}$ value achieved in the DELTA Loop.

\section{(ii) Gas Control System}

The control strategy for the UW - Molten Lead Corrosion Apparatus (MLCA) involves control of the $\mathrm{H}_{2} / \mathrm{H}_{2} \mathrm{O}$ ratio in the cover gas that in turn will regulate the oxygen partial pressure in the system and ultimately the oxygen concentration in the lead. To verify and monitor oxygen concentration levels in the molten lead, a solid state YSZ ceramic sensor with a Pt/air reference will be used to measure the Nernstian potential created by the oxygen concentration difference.

A well-known control strategy for controlling oxidizing environments is the introduction of a $\mathrm{H}_{2} / \mathrm{H}_{2} \mathrm{O}$ mixture to establish the partial pressure oxygen in the system.

$$
\mathrm{H}_{2}+\frac{1}{2} \mathrm{O}_{2}=\mathrm{H}_{2} \mathrm{O}
$$

The free energy of formation for $\mathrm{H} 2 \mathrm{O}$ is well known, leading to the following reaction equilibrium:

$$
\frac{P_{\mathrm{H}_{2} \mathrm{O}}}{P_{\mathrm{H}_{2}} P_{\mathrm{O}_{2}}{ }^{1 / 2}}=\exp \left(-\frac{\Delta F_{\mathrm{H}_{2} \mathrm{O}}^{0}}{R T}\right)
$$

One can then determine at what $\mathrm{H}_{2} / \mathrm{H}_{2} \mathrm{O}$ ratio certain metals will form oxides. In the case of steel in the molten lead environment, one would like to establish an environment that allows for the formation of $\mathrm{Fe}_{3} \mathrm{O}_{4}$ (protective oxide scales) but will not form $\mathrm{PbO}$ (contamination). See Figure 40 for the graphical representation of these limits. The gas system must thus be able to control the ratio of $\mathrm{H} 2$ and $\mathrm{H} 2 \mathrm{O}$ within the limits of $1 \times 10^{1}$ and $1 \times 10^{-4}$. 


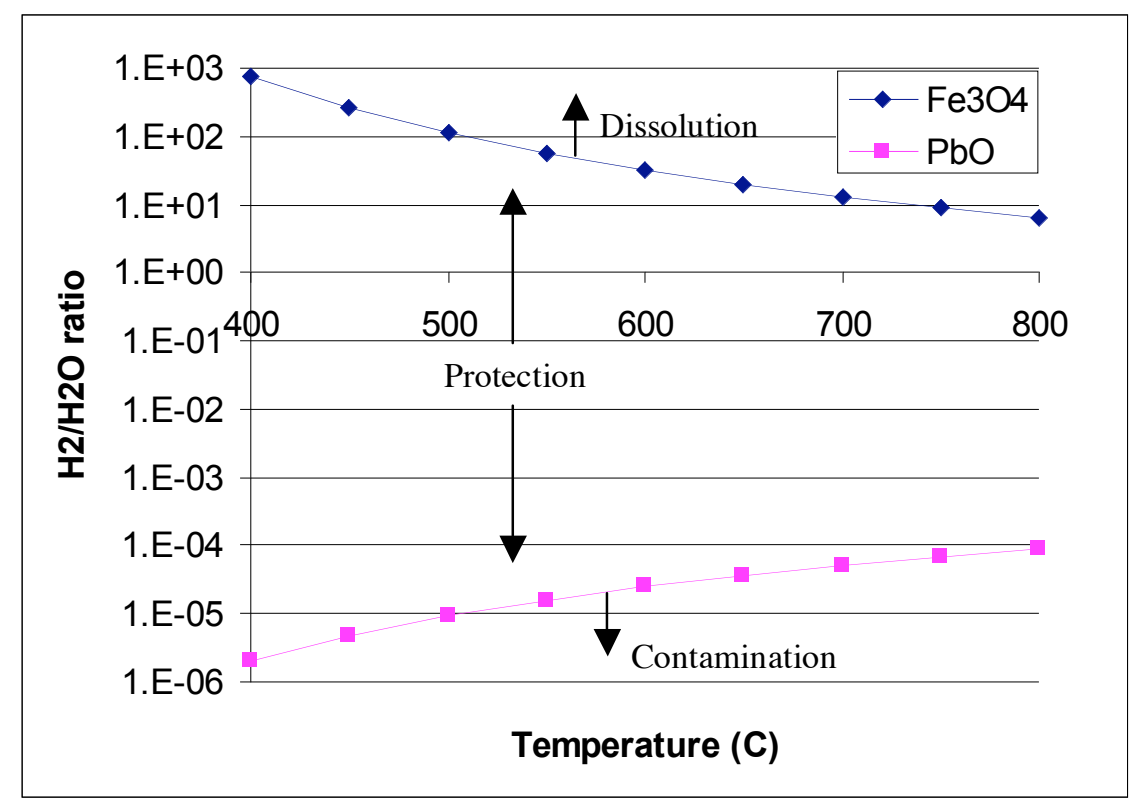

Figure 40- Limiting H2/H2O ratios for Pb-Fe-O system.

\section{(iii) Oxygen Sensor}

Considerable work has been performed on the development of solid-state YSZ oxygen sensors for use in liquid lead and lead-bismuth. They operate on the principle that a difference of oxygen concentrations on the lead and reference sides of the ceramic will generate a potential described by the Nernst equation:

$$
E_{N}=\frac{R T}{4 F} \ln \frac{P_{O_{2}(r e f)}}{P_{O_{2}(P b)}}
$$

Since the reference oxygen content is known, (as are gas constant R, absolute temperature T, and Faraday constant F), one can determine the concentration of oxygen in the melt from the electromotive force (EMF) generated by the electrode. For a Pt/Air reference, relations for saturated and unsaturated systems are given by Courouau, et al (in V):

$$
\begin{aligned}
& E_{\text {sat }, T}=1.129-5.858 \times 10^{-4} T \\
& E_{C o, T}=.791-4.668 \times 10^{-4} T-4.309 \times 10^{-5} T \ln C_{0}
\end{aligned}
$$

and by Muscher, et al (in $\mathrm{mV}$ ):

$$
\begin{aligned}
& E_{\text {sat }, T}=1136.06-.5762 T \\
& E_{C o, T}=794.09-.06085 T-.0431 T \ln C_{0}
\end{aligned}
$$

along with the useful relation relating $\mathrm{EMF}(\mathrm{mV})$ to the $\mathrm{H}_{2} / \mathrm{H}_{2} \mathrm{O}$ ratio:

$$
E_{\mathrm{H}_{2} / \mathrm{H}_{2} \mathrm{O}, \mathrm{T}}=1260.92-.293 \mathrm{~T}+.043 \mathrm{~T} \ln (\mathrm{H} 2 / \mathrm{H} 2 \mathrm{O})
$$


It must be recognized that while these relations may provide quantitative measures, realistically the actual results may vary and no definitive quantitative declarations can be made. It is therefore important that the sensor and gas system be tested and calibrated such that the response of the system to transients may be observed with the sensor while ultimate control lies with the thermodynamic regime established by the gas system. The gas system itself consists of two gas streams, ultra-high purity Ar with a $\mathrm{H}_{2} \mathrm{O}$ bubbler and a $4 \% \mathrm{H}_{2} / \mathrm{UHP}-$ Argon mixture. A relative humidity sensor verifies proper saturation of the $\mathrm{H}_{2} \mathrm{O} / \mathrm{Ar}$ stream and digital flow meters will ensure proper flow ratio.

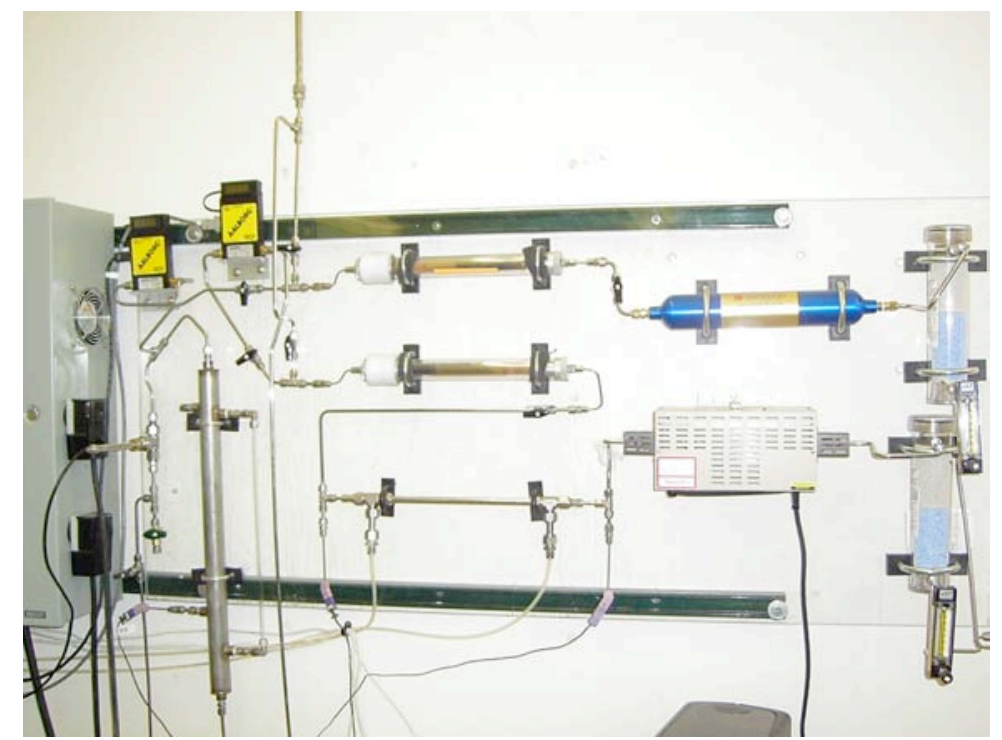

Figure 41- Oxygen Control Gas System.

The sensor test was carried out in a glovebox to better control the atmospheric condition of the experiment. It consists of a lead containing crucible, a ceramic fiber heater, theremocouples in and around the lead and heater, and the sensor itself (Figure 28). The sensor is based on a design by Scott Lillard at Los Alamos National Laboratory and is comprised of a long yttria-stabilized-zirconia (YSZ) tube with a small amount of platinum powder and a platinum leadwire. The open end of the tube is vented to the outside air. To minimize the cell resistance, a high-impedance electrometer is used to measure the voltage between the $\mathrm{Pb}$ and the $\mathrm{Pt}$ leadwire. A LabView program is used for data acquisition and temperature control (Figure 43). 


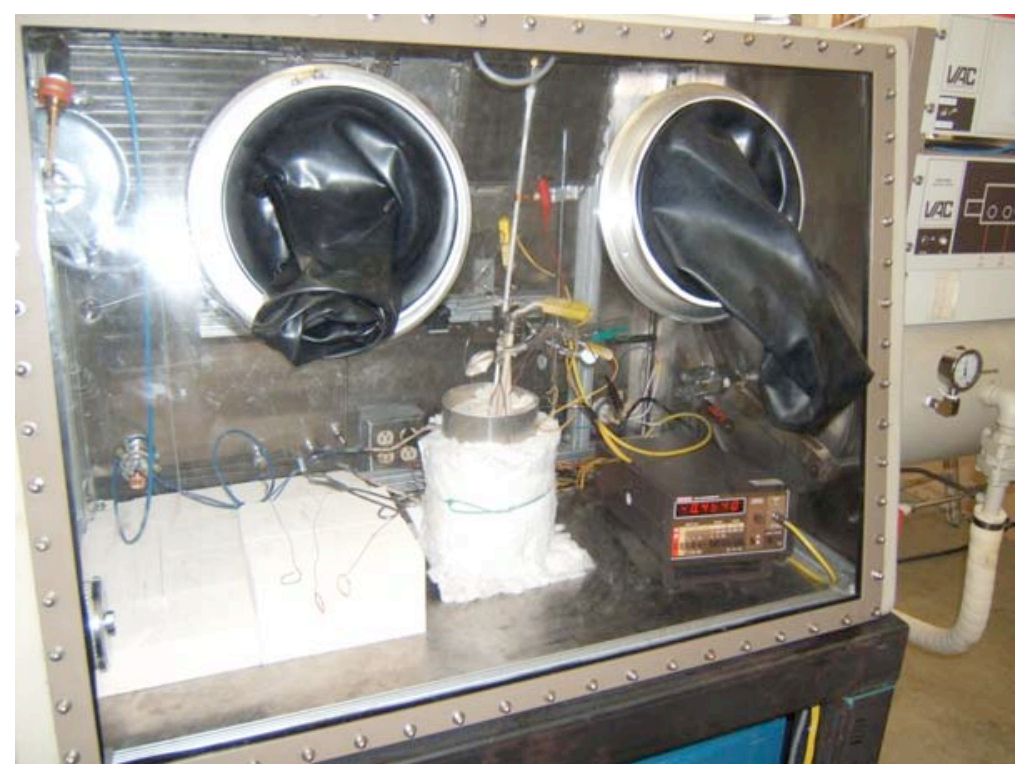

Figure 42 - Sensor Test Glovebox setup.

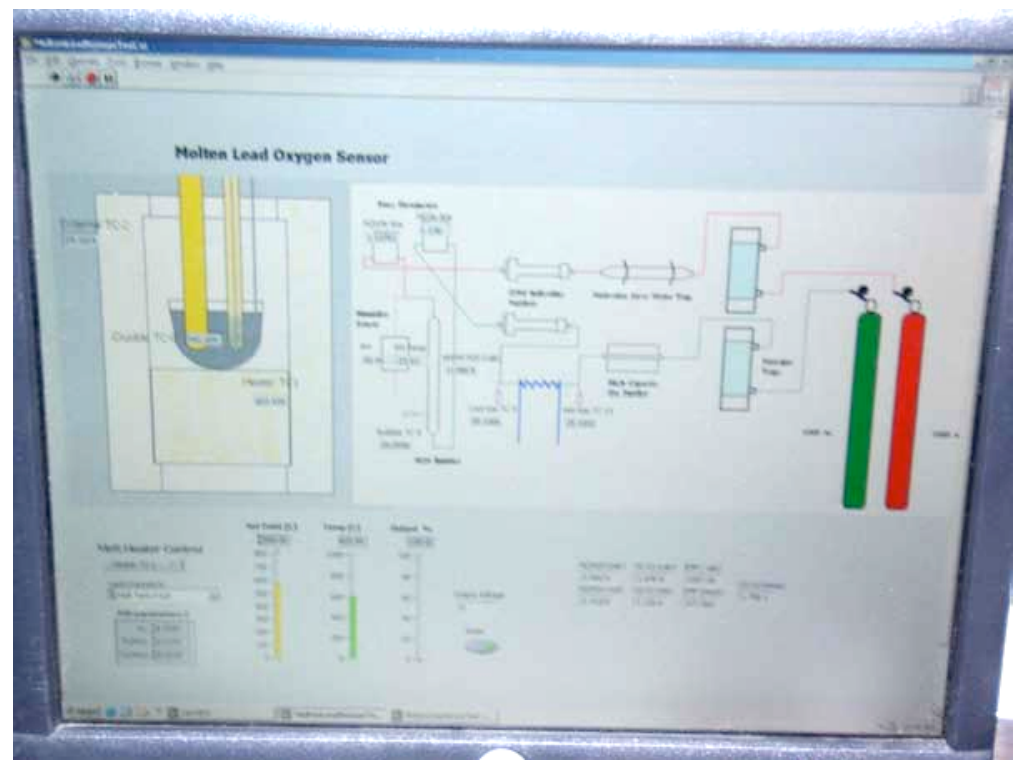

Figure 43 - Sensor Test Lab View Console.

\section{Conclusions}

Corrosion experiments were performed to study the corrosion behavior of and effects of several surface modifications to ferritic-martensitic steels in molten lead-bismuth eutectic under conditions similar to what would be found in a lead-cooled fast reactor. After extensive characterization and analysis of the exposed materials' surfaces, several significant conclusions and recommendations can be drawn from the results.

As theory predicts, the steels formed a protective duplex oxide layer consisting of an outer magnetite $\left(\mathrm{Fe}_{3} \mathrm{O}_{4}\right)$ layer and an inner Fe-Cr spinel $\left((\mathrm{Fe}, \mathrm{Cr})_{3} \mathrm{O}_{4}\right)$ layer which is sometimes accompanied by an $\mathrm{O}$-enriched and $\mathrm{Fe}$-depleted diffusion zone at the oxide-bulk interface. In accordance with the Tedmon Model, the outer magnetite layer is removed by the melt over time and the underlying spinel layer serves to mitigate more catastrophic corrosion degradation such as dissolution and liquid metal attack along grain boundaries. However, 
studies suggest that despite the protective nature of the $\mathrm{Fe}-\mathrm{Cr}$ oxides formed, current materials may not be able to withstand the demanding lifetime requirements ( $>20$ years) for proposed reactor components.

Based on the promise of the plasma-assisted elemental surface treatments in this experiment, it is recommended that further studies be carried out to further investigate the benefits and feasibility of implementing this technology. Based on variations in the surface modified samples and localized failures of some of the protective layers, improvement of the quality and uniformity of these surface treatments is necessary to realize the maximum enhancement of corrosion performance. Additionally, it is not clear that the tests are long enough for corrosion to approach asymptotic kinetics, or whether other transitions or mechanisms will appear in time. Extended tests will of course be needed to validate the improved surface treatments.

Surface roughness does have a significant effect on the corrosion behavior of steel in liquid lead-bismuth. The rougher surfaces will tend to form a thicker oxide, retain an outer magnetite layer longer and demonstrate intergranular corrosion, whereas the smoother surfaces tend to have a smooth LBE/oxide interface and thinner oxide layers followed by an oxygen enriched diffusion zone. For application to a lead-alloy cooled fast reactor, it is recommended that materials be polished to a roughness perhaps comparable to the 800 grit samples $\left(\mathrm{R}_{\mathrm{q}} \sim .02\right)$ to promote a uniform protective oxide layer with minimal intergranular attack while still promoting long-term adherence of the oxide film and remaining costeffective.

The shot peening treatment showed promise in the earlier stages of the experiment by forming a uniform protective oxide layer and inhibiting intergranular attack. However, once the oxide layer grew past the affected region of the treatment this protective capacity appears to have diminished. If the treatment could be made to have a deeper affected region by increasing the process time or pressure (or better yet, use a material that is entirely nanocrystalline) it may be possible to enhance the corrosion performance of steels for a more extended period of time. Nonetheless, if the oxide layer is to retreat into the bulk as the oxide is removed and mass is transferred through the scale, then the protective capacity of the shot peening treatment may be limited by the affected depth.

A model has been adapted to understand important mechanisms of complex oxide formation and removal for 9-12Cr ferritic martensitic steels in molten lead-alloy coolant. The model can estimate the early stage kinetics for the complex scale as well as long term materials thinning rate under the assumption that the scale is within its mechanical stability limits so that the protective oxide scale (in this case, the Fe-Cr spinel) remains intact and adherent. Tedmon's equation, Wagner oxidation theory, and mass transfer corrosion theory have provided theoretical values for growth and removal rate constants for the oxide scale. Experimental data has been used to benchmark the calculated values; The parabolic oxide growth rate constant was determined to be on the order of $1 \times 10^{-16} \mathrm{~m} 2 / \mathrm{s}$, and the scale removal rate constant on the order of $2 \times 10^{-12} \mathrm{~m} / \mathrm{s}$, leading to long-term material loss rate of about 40 $\mu \mathrm{m} / \mathrm{yr}$. For a twenty year application, as is proposed by current LFR designs, this translates to nearly $1 \mathrm{~mm}$. While this may be within design limits for certain structural materials, potential cladding materials would be on the order of $1 \mathrm{~mm}$, indicating that other techniques such as surface treatments or preoxidation may be necessary to meet cladding materials requirements. It is also interesting to see that while the limiting oxide thickness may vary from alloy to alloy, the long-term material thinning rate is fairly consistent. This means that 
measurement of the total oxide thickness at a given time is not necessarily the best metric for predicting corrosion performance of a particular material. Rather, the growth and removal processes most both be accounted for over time to accurately assess the corrosion performance. Furthermore, future modeling work including better long term ( $>5000$ hours) materials performance estimates and experimental weight gain measurements will allow for the development of a superior evaluation technique. Additional recommendations for future studies would include examination of the overall durability and impermeability of the protective spinel layer once the outer magnetite is removed and incorporation of the internal oxidation layer to the model. Finally, improvements to the input parameters for the theoretically obtained parabolic growth and removal rate constants, particularly those to which the calculation is particularly sensitive such as the partial pressure of oxygen at the interfaces, would further reinforce and validate the model.

\section{References}

i. T. ALLEN, R. KLUEH, N. LI, "Lead-cooled Fast Reactor: Survey of Materials Research and Development Needs" Initial Generation IV Reactors Integrated Materials Technology Program Plan, ORNL/TM-2003/244 (2003).

ii. J. ZHANG, N. LI, "Oxide Mechanism of Steels in Liquid-Lead Alloys", Oxidation of Metals, v. 63, iss. 5/6 (2005).

iii. F. BARBIER, A. RUSANOV, "Corrosion behavior of steels in flowing lead-bismuth", Journal of Nuclear Materials, v. 296 p. 231-236 (2001).

iv. T. FURUKAWA, G. MÜLLER, G. SHUMACHER, A, WEISENBURGER, A. HEINZEL, F. ZIMMERMAN, K. AOTO, "Corrosion Behavior of FBR Candidate Materials in Stagnant $\mathrm{Pb}-\mathrm{Bi}$ at Elevated Temperatures.” Journal of Nuclear Science and Technology, (2004).

v. J. ZHANG, N. Li, "Review of Studies on Fundamental Issues in LBE Corrosion." LANL/LA-UR-04-0869 (2004).

vi. E. MCCAFFERTY, "Effect of Ion Implantation on the Corrosion Behavior of Iron, Stainless Steels, and Aluminum-A Review" Critical Review Of Corrosion Science And Engineering, NACE Corrosion, v. 57, no. 12. (2001).

vii. A. ANDERS, ed. Handbook of Plasma Immersion Ion Implantation \& Deposition, John Wiley \& Sons, New York, (2000).

viii. M. KONDO, M. TAKAHASHI, S. YOSHIDA, N. SAWADA, Proceedings of ICAPP '04, paper 4044, p. 2061-2068, Pittsburgh, PA, (2004).

ix. D. H. HUR, M. S. CHOI, D. H. LEE, M. H. SONG, S. J. KIM, J. H. HAN, "Effect of shot peening on primary water stress corrosion cracking of Alloy 600 steam generator tubes in an operating PWR plant", Nuclear Engineering and Design, v. 227, iss. 2, Pages 155-160, (2004).

x. H. C. CHOE, K. H. KIM, "Effects of Shot Peening on the Intergranular and Pitting Corrosion Behavior of AISI 316 Stainless Steel," Journal of the Korean Institute of Metals and Materials (South Korea). Vol. 35, no. 3 (1997). 
xi. K. WOLOSHUN, V. WATTS, and N. LI, Lead-Bismuth Eutectic Coolant for Advanced Nuclear Systems: Operational Experience, ANS Transaction, (2004).

xii. R.L. KLUEH, "Elevated temperature ferritic and martensitic steels and their application to future nuclear reactors." Oak Ridge National Laboratory: Metals and Ceramics Division, ORNL/TM-2004/176, (2004).

xiii. J. LIM, R. G. BALLINGER, E. LOEWEN, "The Effect of Silicon on the Corrosion of Iron in Lead-Bismuth Eutectic," Eleventh International Conference on Nuclear Engineering, ICONE-11 \#36531, Tokyo, Japan, (2003).

xiv. J. NAKANO, Y. MIWA, T. KOHYA, T. TSUKADA, "Effects Of Silicon, Carbon And Molybdenum Additions On IASCC Of Neutron Irradiated Austenitic Stainless Steels," Journal of Nuclear Materials, v. 329-333, p. 643-647. Proceedings of the 11th International Conference On Fusion Reactor Materials, (ICFRM-11) Kyoto, Japan, (2004).

xv. L. TAN, M. MACHUT, K. SRIDHARAN, T. ALLEN, "Oxidation Behavior of HCM12A Exposed in Harsh Environments" Trans. American Nuclear Society Annual Conference, Reno, NV, vol. 94, p.745, June (2006).

xvi. J. ZHANG, N. LI, Y. CHEN, "Dynamics of high-temperature oxidation accompanied by scale removal and implications for technological applications." Journal of Nuclear Materials, v. 342, iss. 1-3 (2005).

xvii. X. REN, University of Wisconsin, personal communication (2006).

xviii. M. SCHUTZE, Protective Oxide Scales and Their Breakdown. p. 2-13. Jon Wiley \& Sons, New York. (1997).

xix. C. WAGNER, "Theoretical analysis of the diffusion processes determining the oxidation rate of alloys." Journal of the Electrochemical Society. v. 99 iss. 10, (1952).

xx. F. BARBIER, A. RUSANOV, "Corrosion behavior of steels in flowing lead-bismuth", Journal of Nuclear Materials, v. 296 p. 231-236 (2001).

xxi. Y. MATYCHAK, V. PAVLYNA, V. FEDIRKO, "Kinetics of Selective Oxidation or Chromium Steels in Oxygen-containing Lead." Materials Science. v. 39, no. 5 (2003).

xxii.C. S. TEDMON, "The Effect of Oxide Volatilization on the Oxidation Kinetics of $\mathrm{Cr}$ and Cr-Fe Alloys." Journal of the Electrochemical Society. V. 142, (1967).

xxiii. P. KOFSTAD, High Temperature Oxidation of Metals. Jon Wiley \& Sons, New York. (1966).

xxiv. J. ZHANG, N. LI, "Oxide Mechanism of Steels in Liquid-Lead Alloys", Oxidation of Metals, v. 63, iss. 5/6 (2005).

xxv. J. E. CASTLE, P. L. SURMAN, “The Self-Diffusion of Oxygen in Magnetite.” The Journal of Physical Chemistry, v. 71, no. 13 (1967).

xxvi. G. SAMSANOV, ed., The Oxide Handbook. Plenum Press, New York. (1973).

xxvii. J. ZHANG, N. Li, "Improved Application of Local Models to Steel Corrosion in Lead-Bismuth Loops," Nuclear Technology, v. 144. (2003). 
xxviii. F.D. RICHARDSON, J.H.E. JEFFES, "The Thermodynamics of Substances of Interest in Iron and Steel Making from $0^{\circ} \mathrm{C}$ to $2400^{\circ} \mathrm{C}$ : I-Oxides," J. Iron and Steel Inst. 160 , 261. (1948).

\section{Patents}

None

\section{Publications}

T. R. Allen, L. Tan, Y. Chen, K. Sridharan, M. T. Machut, J. Gan, G. Gupta, G. S. Was, and S. Ukai, Corrosion and Radiation Response of Advanced Ferritic-Martensitic Steels for Generation IV Application, Proceedings of Global 2005, Paper IL001

M. Machut, K. Sridharan, and T. R. Allen, Corrosion of Candidate Materials for Lead-Cooled Reactors, Corrosion 2005, Paper 05590, NACE International, Houston, TX, 2005.

McLean Machut, Kumar Sridharan, Todd Allen, Corrosion of Candidate Materials For LeadCooled Reactors, American Nuclear Society Transactions, Vol. 92 Summer 2005, p. 131.

McLean Machut, Kumar Sridharan, Ning Li, and, Todd Allen, Corrosion Performance of Surface Modified Materials for Lead-Cooled Reactors, Transactions of the 2005 ANS Winter Meeting, Washington, D.C., Vol. 93, November 2005, p. 471.

L. Tan, M. T. Machut, K. Sridharan, and T. R. Allen, "Oxidation Behavior of HCM12A Exposed in Harsh Environments," Transactions of the 2006 ANS Annual Meeting, Reno, NV, Vol. 94, June 2006, p. 745.

M. Machut, K. Sridharan, Ning Li, and T. R. Allen, "Modeling Corrosion Mechanisms of Steels for Lead-Alloy Cooled Reactors," Transactions of the 2006 ANS Annual Meeting, Reno, NV, Vol. 94, June 2006, p. 750.

M. Machut, K. Sridharan, N. Li, and T. Allen, "Effects of Surface Roughness, Shot Peening, and Plasma-Assisted Elemental Surface Modification on Corrosion Resistance of Steels for use in Lead-Alloy Cooled Fast Reactors, Proceedings of the 2007 International Congress on Advances in Nuclear Power Plants, paper \#7221, Nice, France, May 2007.

L. Tan, M. T. Machut, K. Sridharan, and T. R. Allen, "Oxidation Behavior of HCM12A Exposed in Harsh Environments," submitted to J. Nucl. Mater.

M. Machut, K. Sridharan, Ning Li, and T. R. Allen, "Modeling Corrosion Mechanisms of Steels for Lead-Alloy Cooled Reactors," submitted to J. Nucl. Mater. 